OPEN ACCESS

Mitigating PEMFC Degradation During Start-Up: Locally Resolved Experimental Analysis and Transient Physical Modelling

To cite this article: Elena Colombo et al 2021 J. Electrochem. Soc. 168054508

View the article online for updates and enhancements. 


\title{
Mitigating PEMFC Degradation During Start-Up: Locally Resolved Experimental Analysis and Transient Physical Modelling
}

\author{
Elena Colombo, ${ }^{\mathrm{z}}$ (i) Andrea Bisello, (iD) Andrea Casalegno, (iD) and Andrea Baricci (iD \\ Politecnico di Milano, Department of Energy, 20156 Milano, Italy
}

\begin{abstract}
This paper discusses the results of an experimental and modelling activity devoted to the analysis of start-up/shut-down of PEM fuel cells under operative conditions representative of automotive applications, when mitigation strategies are implemented. The focus is on air start-ups after long stops, when permeated air into the anode could not be avoided. A transient and physical 2D model was developed, incorporating the main electrochemical reactions and pseudo-capacitive contributions, calibrated on specific experiments and validated on local measurements of potential and current. Through the simulations, the impact of each phenomenon was separated in the complex dynamics of the process, elucidating the key role of platinum oxides. The experimental measurements comprise the local potentials, provided by through-plate Reference Hydrogen Electrodes, and the in-plane currents, measured among four regions of a segmented hardware. A systematic study of mitigation strategies based on stressors is presented, like: anode flow rate, oxygen dilution and temperature. Their effectiveness results from the ability in reducing either the process duration or the maximum potential. The model helps in interpreting the observed changes and to obtain trends of corroded carbon as a function of stressors; a controlling role is played by the anode flow velocity and the anodic oxygen concentration.

(C) 2021 The Author(s). Published on behalf of The Electrochemical Society by IOP Publishing Limited. This is an open access article distributed under the terms of the Creative Commons Attribution Non-Commercial No Derivatives 4.0 License (CC BYNC-ND, http://creativecommons.org/licenses/by-nc-nd/4.0/), which permits non-commercial reuse, distribution, and reproduction in any medium, provided the original work is not changed in any way and is properly cited. For permission for commercial reuse, please email: permissions@ioppublishing.org. [DOI: 10.1149/1945-7111/abf4eb]
\end{abstract}

Manuscript submitted December 18, 2020; revised manuscript received March 13, 2021. Published May 7, 2021. This paper is part of the JES Focus Issue on Proton Exchange Membrane Fuel Cell and Proton Exchange Membrane Water Electrolyzer Durability.

Supplementary material for this article is available online

\section{List of symbols}

$\mathbf{a}_{\mathbf{j}} \quad$ Activity of species/-

Area segment geometric area $/ \mathrm{cm}^{2}$

A

$\mathbf{A}_{\mathbf{C}}$

C

$\mathbf{C}_{\mathrm{dl}}$

d

D

$\mathbf{E}_{\text {act }}$

$\mathbf{E}^{\mathbf{0 0}}$

$\mathbf{F}$

i

I

$\mathbf{i}_{00}$

$\mathbf{i}_{\text {lim }}$

k

L

$\mathbf{L}_{\mathbf{P t}}$

$\mathbf{L}_{\mathbf{C}}$

$\mathbf{M}_{\mathbf{w}, \mathbf{j}}$

n

$\mathbf{N}_{\mathbf{P t}}$

p

$\mathbf{p}_{\mathbf{j}}$

$\mathbf{Q}_{\mathbf{m}}$

$\mathbf{R}$

$\mathbf{R}_{\text {MT,O2 }}$

$\mathbf{R}_{\mathbf{j}}$

$\mathbf{r f}_{\mathbf{P t}}$

$\mathbf{r f}_{\mathbf{C}}$

$\mathbf{t}^{\mathrm{C}}$

$\mathbf{t}_{\text {res }}$

T

$\mathbf{u}$

Carbon surface area $/ \mathrm{m}^{2}{ }_{\mathrm{C}} \mathrm{g}^{-1}{ }_{\mathrm{C}}$

Species concentration $/ \mathrm{mol} \mathrm{m}^{-3}$

Layer thickness $/ \mu \mathrm{m}$

Diffusivity $/ \mathrm{m}^{2} \mathrm{~s}^{-1}$

Activation energy $/ \mathrm{kJ} \mathrm{mol}^{-1}$

Faraday's constant/C mol ${ }^{-1}$

Current density/ $\mathrm{A} \mathrm{cm}^{-2}$

Total current/A

Permeability $/ \mathrm{m}^{2}$

Channel length $/ \mathrm{m}$

Platinum loading $/ \mathrm{mg}_{\mathrm{Pt}} \mathrm{cm}^{-2}$ geo

Carbon loading $/ \mathrm{mg}_{\mathrm{C}} \mathrm{cm}^{-2}$ geo

Molar mass $/ \mathrm{g} \mathrm{mol}^{-1}$ tion/-

Pressure/kPa

Partial pressure $/ \mathrm{kPa}$

Time/s

Residence time/s

Temperature/K

Velocity/m s ${ }^{-1}$
Platinum surface area $/ \mathrm{m}^{2} \mathrm{Pt}^{-1} \mathrm{Pt}$

Double-layer capacitance/ $\mathrm{F} \mathrm{cm}^{-2}$

Thermodynamically reversible potential of reaction/V

Exchange current density/ $\mathrm{A} \mathrm{cm}^{-2} \mathrm{Pt}$

Limiting current density/A $\mathrm{cm}^{-2}$

Number of atoms transferred in an electrochemical reac-

Maximum surface coverage $/ \mathrm{mol} \mathrm{m}^{-3}$ geo

Total mass source $/ \mathrm{kg} \mathrm{s}^{-1} \mathrm{~m}^{-3}$

universal gas constant $/ \mathrm{J} \cdot \mathrm{K}^{-1} \cdot \mathrm{mol}^{-1}$

Oxygen mass transport resistance/s $\mathrm{m}^{-1}$

Reaction rate of species $/ \mathrm{kg} \mathrm{s}^{-1} \mathrm{~m}^{-3}$

Platinum roughness factor $/ \mathrm{m}^{2} \mathrm{Pt}^{-2}$ geo

Carbon roughness factor $/ \mathrm{m}^{2} \mathrm{~m}^{-2}$ geo

\begin{tabular}{|c|c|}
\hline V & Volume $/ \mathrm{m}^{3}$ \\
\hline$\dot{\boldsymbol{V}}$ & Volumetric flow rate $/ \mathrm{m}^{3} \mathrm{~s}^{-1}$ \\
\hline $\mathbf{x}$ & Modelling domain axis, along channel direction \\
\hline $\mathbf{y}$ & Modelling domain axis, through membrane direction \\
\hline Greek & \\
\hline$\alpha$ & Charge transfer coefficient/- \\
\hline$\Delta \mathbf{E}$ & Potential temperature coefficient/ $\mathrm{V} \mathrm{K}^{-1}$ \\
\hline$\varepsilon$ & Porosity/- \\
\hline$\eta$ & Overpotential/V \\
\hline$\dot{\theta}$ & Percentage coverage at Pt surface/- \\
\hline$\lambda$ & Stoichiometry/- \\
\hline$\mu$ & Dynamic viscosity/Pa s \\
\hline$\rho$ & Density $/ \mathrm{kg} \mathrm{m}^{-3}$ \\
\hline$\sigma_{1}$ & Proton conductivity/S m ${ }^{-1}$ \\
\hline$\sigma_{\mathrm{s}}$ & Electronic conductivity/S m ${ }^{-1}$ \\
\hline$\tau$ & Tortuosity/- \\
\hline$\phi_{1}$ & Potential in the membrane phase/V \\
\hline$\phi_{\mathrm{s}}$ & Potential in the solid phase/V \\
\hline$v$ & Stoichiometric coefficient/- \\
\hline$\omega$ & $\mathrm{PtOH}-\mathrm{PtOH}$ or $\mathrm{PtO}-\mathrm{PtO}$ interaction parameter $/ \mathrm{J} \mathrm{mol}^{-1}$ \\
\hline$\omega_{\mathbf{j}}$ & Mass fraction of species/- \\
\hline
\end{tabular}

Durability is one of the central issues of polymer electrolyte membrane fuel cells (PEMFC) for automotive, mainly because of the dynamic load profile and the frequent stops that typically are required by this application. Specifically, on/off periods may occur with a certain frequency that depends on the vehicle utilization and the energy management strategy implemented, but from a durability point of view a distinction is to be made between short stops and a complete system shut-down over a long time. In this last case, the ambient air is supposed to leak into the stack, specifically in the anode compartment, leading to the onset of a hydrogen/air front. The front develops when the system is started again and the fuel injected from the tank displaces the leaked air. Air start-up and shut-down events are recognized as potential critical issues for the fuel cells longevity. ${ }^{1,2}$ The simultaneous presence of both air and hydrogen at the anode causes a rise of the local potential at the cathode to values as high as $1.5 \mathrm{~V}$. This mechanism, named reverse-current decay by Reiser et al., ${ }^{3}$ could lead to a severe corrosion of the carbon based 
catalyst support. ${ }^{4}$ From Reiser's work in the 2005, several experiments were successfully designed to investigate this process and it was verified that it significantly damages the catalyst layer structure and it is strongly heterogeneous. ${ }^{5-8}$ Significant carbon corrosion was observed by SEM images, both as holes formation ${ }^{7,9}$ and catalyst layer thinning, due to loss of porosity. ${ }^{5,10}$ Catalyst particles could be detached because of the weakened attachment to the carbon surface, ${ }^{11}$ but also $\mathrm{Pt}$ agglomeration and Pt dissolution/precipitation within the electrolyte were observed. ${ }^{12}$ The theoretical fundamentals that confirmed these findings were captured by a kinetic model proposed by Meyer and Darling ${ }^{13}$ and later by $\mathrm{Gu}$ et al., ${ }^{14,15}$ who included also the pseudo-capacitive currents with a lumped parameter approach, considering both the $\mathrm{Pt}$ oxide reactions and the double-layer effects. A detailed description of the process dynamics was then provided by Maranzana et al., ${ }^{16}$ who simulated quantitatively the internal start-up currents and potentials by a pseudo $2 \mathrm{D}$ model, including oxidation/reduction reactions for the catalyst. To simplify the numerical solution, the in-plane gas concentration was imposed as a boundary condition, solving the mass transport in the through-plane direction. Chen et al. ${ }^{17}$ introduced for the first time the anode channel in the start-up model, but again using a 1D+1D representation; gas replacement through a reacting flow is a highly stiff phenomenon difficult to solve numerically in a reasonable computational time. Only recently, Randrianarizafy et al. ${ }^{18}$ developed a pseudo 3D model.

To limit the impact of start/stop events, several mitigation strategies are today applied in PEMFC systems. Mitigation strategies could be divided according to two complementary approaches: the adoption of strategies at the system level and the development of materials tolerant to support corrosion. A large literature was devoted to the analysis of the main stressors that could minimize the impact of degradation associated to start-up and shut-down. Useful reviews for the mitigation strategies could be found in the works of Zhang et al., ${ }^{19} \mathrm{Yu}$ et al. ${ }^{20}$ and Ren et al.. ${ }^{21}$ The most relevant stressors were identified as temperature, ${ }^{4,22-25}$ gas residence time $^{24,26}$ and relative humidity ${ }^{25,27-30}$ by means of repeated startstop experiments or specifically accelerated stress tests (AST). Accelerated tests are effective at isolating the ageing mechanism of support corrosion, ${ }^{11,31}$ such to provide in a short time materials benchmark, but not realistic from a real world operating standpoint. They are indeed carried out at uniform and selected stressors, while real start-up/shut-down are heterogeneous processes that involve multiple degradation modes, ${ }^{12}$ as explained above.

Thanks to the scientific results available in literature, automotive state-of-the-art systems implement comprehensive strategies ${ }^{32-35}$ that obliterate the impact of shut-down on degradation, as well as of start-up after a short stop. Real systems keep the hydrogen in the anode for prolonged periods to avoid air at the re-start or apply small electrical loads: these solutions eliminate high cell voltage $(>1 \mathrm{~V})$ in a leak-free stack design. On the other hand, the issues related to the hydrogen/air front formation could not be completely eluded since air leaks into the stack after a long stop time. The time required by the ambient air to permeate into the stack is quite long (>days) compared to the time needed to cool the stack down to ambient temperature ( $>$ hours), thus a low temperature is guaranteed during an air start-up. Low temperature is a condition that is known to mitigate the corrosion of the carbon support. ${ }^{4}$ However, only a few studies have experimentally analyzed the degradation rate under ambient temperature start-ups. ${ }^{8,27}$ Mittermeier et al. ${ }^{36,37}$ exploited a pseudo-dynamic 0D model to assess the carbon support degradation for a wide range of temperature values, including ambient temperature. Similarly to temperature, other parameters have been designed to reduce the start-up/shut-down degradation rate in real systems: for example, a high hydrogen flow rate minimizes the transient duration. At the state-of-the-art, large anode flow rates limit the transient residence time to values lower than $1 \mathrm{~s} .{ }^{14}$

Start/stops are still to be fully characterized in their dynamics in order to refine mitigation strategies, with the purpose of further improving those solutions already implemented in stacks. The aim of this work is to explore the role of stressors on the degradation occurring in a membrane electrode assembly (MEA) with corrosion tolerant catalyst, which is exposed to start-up events under mitigated conditions, i.e. low temperature and short residence time. Other degradation studies in literature were devoted to start-up/shut-down and implemented a methodology consisting in ageing tests performed under different operating conditions, which allowed to evaluate the impact of stressors by comparing the evolution of known metrics e.g. catalyst active surface, carbon dioxide emissions. ${ }^{11,36,38,39}$ In this work, a reference start-up case is adopted following the specifications of the ID-FAST European project durability test program. It is studied in the details of its dynamics by measuring the local currents and the local potentials that drive the degradation. A detailed, local analysis of start-up under different operating conditions is then performed. A systematic approach is followed to investigate the major stressors, e.g. temperature, residence time, oxygen partial pressure. Experimentally, an array of through-plate Reference Hydrogen Electrodes (RHE's) was implemented, to provide a spatially resolved operando measurement of each electrode potential. By the way of this technique, only limited attempts to measure the in-situ potential for this process can be found in literature, ${ }^{9,40}$ mostly focusing on the cathode side. RHE's were introduced in this work both at the cathode and at the anode to track the evolution of the local voltage profile. In addition, some research groups quantified the in-plane currents in fuel cells during start-up and the induced local degradation by adopting segmented hardware, ${ }^{41-45}$ possibly combined with shunt resistors $^{46,47}$ or microstructured flowfield. ${ }^{6}$ In this work, the setup for the local potentials measurement was coupled with an innovative methodology for recording the in-plane current generated during start-up/shut-down in a four macro-segmented hardware; the aim is to track all the local data of potential and current density with an extremely high temporal resolution, in the order of milliseconds. The theoretical support of a validated physics-based 2D transient model was included to provide an insight into the complexity of this process and disentangle the superimposition of phenomena. The model is a necessary tool to determine each single contribution among the reactions taking place and to estimate the amount of carbon corroded. To the authors' best knowledge, this is the only model that combines kinetic, mass transport and pseudo-capacitive contributions (double-layer and Pt oxides) in a 2D domain, without imposing the concentration of gases along the anode channel as a boundary condition. The mixing of the gases is allowed, resulting in not a steep separation between the "passive" and the "active" regions. Most of all, it is the first time that such a model was validated on multiple local measurements carried out over a wide range of operative conditions. The result is a useful tool for evaluating the effects of mitigation strategies by predicting the amount of carbon corroded.

\section{Experimental}

Hardware and setup.-A segmented cell hardware with an active area of $5 \mathrm{~cm} \times 5 \mathrm{~cm}$ was adopted for this work, described in papers $^{48,49}$ and shown in Fig. 1. The flowfield for both cathode and anode consists of a triple serpentine made by three parallel channels, that are $54 \mathrm{~cm}$ long. Channels are $0.9 \mathrm{~mm}$ deep and $1 \mathrm{~mm}$ wide, on both the sides. Lands are $1 \mathrm{~mm}$ wide too. Both at anode and cathode, the graphite flow plates are segmented into four sections, such to separate four MEA portions of active area: segment $1=5.832 \mathrm{~cm}^{2}$, segment $2=5.797 \mathrm{~cm}^{2}$, segment $3=7.652 \mathrm{~cm}^{2}$ and segment $4=$ $5.719 \mathrm{~cm}^{2}$. Segmentation cuts were realized on the ribs to prevent alterations in channel cross section. Four indipendent gold plated current collectors per side draw the current. The setup ensures a complete electrochemical characterization of each segment while limiting internal border effects and avoiding crosscurrents and reciprocal interference between segments; the limited invasiveness of the setup has been demonstrated in other works. ${ }^{48,49}$ The gas feed configuration is co-flow (anode gas and cathode gas flow in the same 


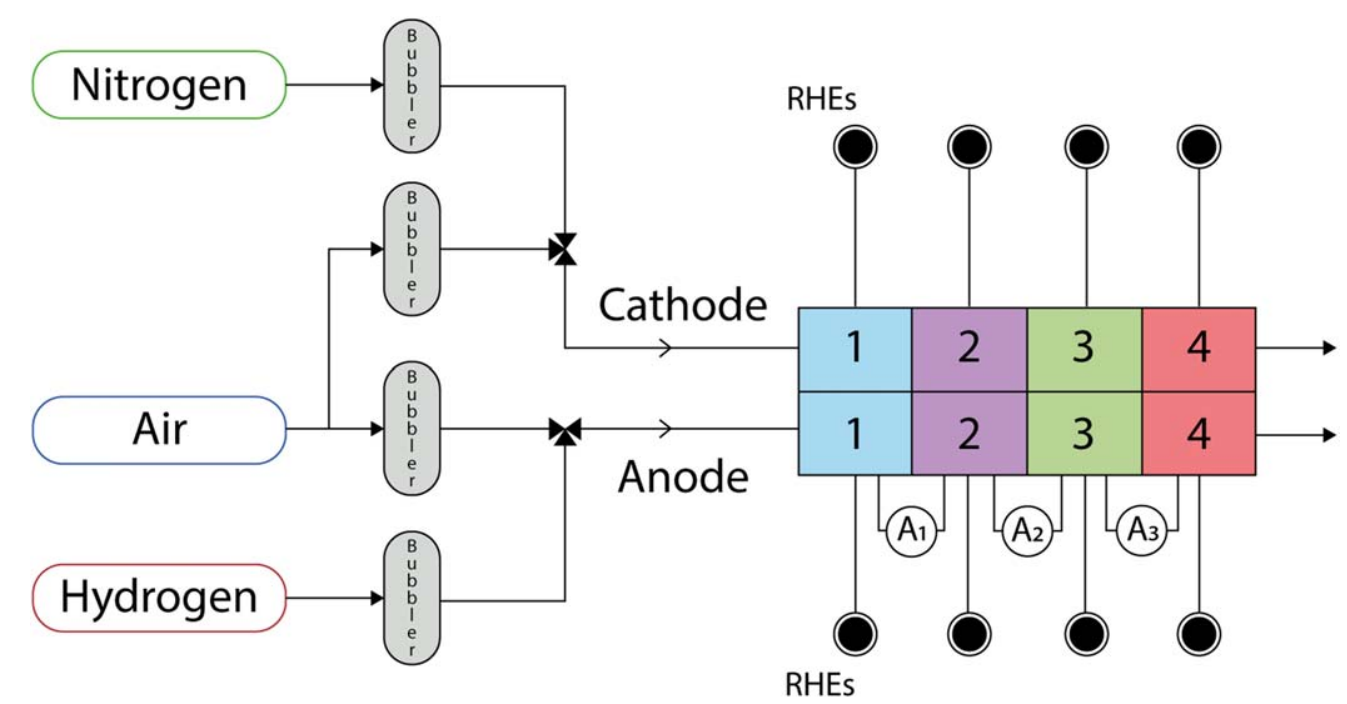

Figure 1. Schematic of the experimental configuration for the simulation of start-up/shut-down, based on gas switching through three-way valves. The tools for the measurement of the local potential (RHE's) and in-plane currents (source measure units) are evidenced in the drawing of the segmented hardware. The current setup could be applied either at the anode or at the cathode side.

direction). The segments are numbered from 1 to 4 in the direction of the flows, such that segment 1 encompasses the cathode inlet/anode inlet while segment 4 includes the cathode outlet/anode outlet. At the anode side, both hydrogen and air are provided by the same inlet, for start-up and shut-down reproduction, respectively.

The measurement of the local potentials is realized by a throughplate arrangement of Reference Hydrogen Electrodes (RHE's). This innovative technique $e^{50-53}$ was just recently applied to study the local evolution of potentials during start-ups by Brightman and Hinds ${ }^{40}$ and Aparicio-Ferreira et al.. ${ }^{38}$ A salt bridge is created using a small Nafion tubing (Perma Pure, NJ, USA. Internal diameter of $0.6 \mathrm{~mm}$, external diameter of $0.8 \mathrm{~mm}$ ), placed inside a PTFE tubing, both of approximately $0.1 \mathrm{~m}$ length. An array of holes through the bi-polar plate, the current collector and the end plate permits to insert the tubes to get in contact with the GDL, while the other end is immersed in a vessel. In the flowfield, holes are placed under the land to ensure the direct contact of the tubes with the GDL while limiting the interplay with the gas flowing in the channels. On the GDL extremity, a PEEK filament $(0.45 \mathrm{~mm}$ diameter $)$ is plugged in to ensure better mechanical properties. On the external surface of the flow-field, an O-ring arrangement works as gastight, preventing the leakages. The vessel is full of $0.5 \mathrm{M} \mathrm{H}_{2} \mathrm{SO}_{4}$ and holds the hydrogen reference electrode (Reference Electrode HydroFlex by Gaskatel); it works through a hydrogen cartridge, connected to a PlatinumPalladium-electrode. To avoid dehydration and maintain thus a good ion-conductive path, the Nafion tubing is filled by the same $0.5 \mathrm{M} \mathrm{H}_{2} \mathrm{SO}_{4}$ acid. To ensure a direct ionic connection to the external surface of the electrode, some very small holes have been made in the GDL $(\mathrm{d}=0.9 \mathrm{~mm})$, filled up by a mixture of liquid Nafion and propanol. The propanol evaporates in time; after a hour from mixture application, the GDL is considered ready for use.

Start-up currents are expected to occur in the in-plane direction. In segmented hardware, some research groups tried to measure their values, exploiting small shunts or analogous systems, ${ }^{41,46}$ while Schneider et al. ${ }^{6}$ adopted a microstructured flow field to identify the lateral and local current flowing through channel and land areas. The in-plane current was measured in the present work through three high-precision source-measure units (SMU) modules (NI PXIe4139) that are used to impose $\Delta \mathrm{V}_{\text {segj-seg } j+1}=0$, i.e. no voltage difference subsists between one segment and its consecutive. The units, schematically drawn in Fig. 1 as $A_{1}, A_{2}, A_{3}$, operate as current sources/loads to compensate the variations caused by the hydrogen (or air) supply to the anode. The same configuration could be applied equally either at anode or at cathode. The adopted setup guaranteed a high accuracy. For a range of $3 \mathrm{~A}$, current measurement resolution is $1 \mu \mathrm{A}$ while the accuracy is the $0.082 \%$ of the current value + $900 \mu \mathrm{A}$. For a range of $6 \mathrm{~V}$, voltage measurement resolution is $1 \mu \mathrm{V}$ while the accuracy is the $0.02 \%$ of the voltage value $+300 \mu \mathrm{V}$. Acquisition time was of $10 \mathrm{~ms}$. Such fast and accurate recordings permitted to deeply characterize the current evolution in time under different stressors, even for the rapid and automotive-like transients.

From the compensation currents $\mathrm{I}_{1}, \mathrm{I}_{2}, \mathrm{I}_{3}$ (drawn by the units $\mathrm{A}_{1}$, $\mathrm{A}_{2}, \mathrm{~A}_{3}$ as explained above), the current density $i$ generated/ consumed by each segment $j$, which ranges between 1 and 4 , is computed according to Eq. 1:

$$
i_{\text {seg } j}=\frac{I_{j}-I_{j-1}}{\text { Area }_{\text {seg } j}}, \text { with } I_{0}=I_{4}=0
$$

The summation of all the current contributions should be equal to zero both for anode and cathode due to charge conservation.

Membrane electrode assembly and conditioning.-The CCM is supplied by Johnson Matthey Fuel Cells Ltd. (JMFC, UK) and consisted of a polymer electrolyte membrane $(15 \mu \mathrm{m}$ thick $)$ and $\mathrm{Pt} / \mathrm{C}$ electrodes. $\mathrm{Pt}$ loadings are of $0.4 \mathrm{mg} \mathrm{cm}^{-2}$ (cathode) and $0.08 \mathrm{mg} \mathrm{cm}^{-2}$ (anode) and MEA is assembled with Freudenberg GDL (H14CX483, $150 \mu$ m thick), compressed to $80 \%$ with the use of hard gaskets. Electrode carbon support is highly carbon-corrosion resistant. The MEA is conditioned at $65{ }^{\circ} \mathrm{C}, 100 \% \mathrm{RH}$, outlet ambient pressure and constant stoichiometry of 2/4 at anode and cathode respectively: the current density was varied between $0.2 \mathrm{~A} \mathrm{~cm}^{-2}$ and $0.8 \mathrm{~A} \mathrm{~cm}^{-2}$ every $120 \mathrm{~s}$ and the MEA performance stability checked every $40 \mathrm{~min}$ at $0.5 \mathrm{~A} \mathrm{~cm}^{-2}$. The conditioning procedure lasted for about $17 \mathrm{~h}$ until a stable condition was reached.

Start-up/shut-down procedure.-A specific procedure was designed to simulate a real mitigation strategy of start-up/shut-down: after $\mathrm{H}_{2} /$ air $\mathrm{OCV}$, nitrogen is fluxed into the cathode $(5 \mathrm{~min})$, in order to accelerate but reproduce the complete consumption of oxygen that occurs during the real long shut-down, that ensures the mitigation effect. Then, air is fluxed first into the anode (for $120 \mathrm{~s}$ ) and then into the cathode (for $120 \mathrm{~s}$ ) to reach the air/air long stop condition, consequence in real systems of air leakages. The chosen holding times, for all the gas-filling configurations, were sufficient to guarantee the stabilization of the readings provided by the Reference Hydrogen Electrodes. Finally, the hydrogen flow is introduced into the anode compartment to mimic the start-up. 
The reference operating condition during air start-up was set in accordance with the automotive and industrial partners in the frame of the H2020 European ID-FAST Project, representing a situation that considers mitigation strategies and reproduces a realistic start event after a long stop, as described in the introduction section. According to these strategies, most of the experiments were carried out in this work at a temperature close to ambient $\left(30{ }^{\circ} \mathrm{C}\right)$ and at fully humidified conditions. This parameter was in general not varied to ensure a sufficiently good ionic path for the measurement of the local potential by RHE. All the experiments were performed at ambient pressure. The reference hydrogen flow is set at an equivalent value of $1 \mathrm{~A} \mathrm{~cm}^{-2}$, i.e. $175 \mathrm{ml} \mathrm{min}^{-1}$ of dry gas. The same flow rate has been used for air at the anode side, while the dry cathode flow is $417 \mathrm{ml} \mathrm{min}^{-1}$, for both air and nitrogen. Hydrogen dry flows different from the reference value were applied to investigate the specific effect of $(i)$ the residence time, at fixed temperature and relative humidity, (ii) the operating temperature, at constant residence time and relative humidity. In addition, some oxygen concentrations at the anode were tested. In this case, diluted air is fluxed into the anodic channels prior to start-up. A proper mixture of air and nitrogen was set to guarantee the desired percentage of oxygen, keeping fixed the total $175 \mathrm{ml} \mathrm{min}^{-1}$ of dry gas. The specific parameters for the stressor analysis are later reported in the dedicated sections.

The dataset of the results included in this work is reported on Zenodo (doi:10.5281/zenodo.4684393).

\section{Modelling}

Model description.-The geometry of the physics-based dynamic 2D model, developed in COMSOL Multiphysics, is reported in Fig. 2 and includes seven layers: 2 channels, 2 gas diffusion layers (GDL's), 2 catalyst layers (CL's) and the membrane. The kinetic model solves the main electrochemical reactions, namely HOR and ORR/OER at the anode electrode, ORR/OER and COR at the cathode electrode, and $\mathrm{Pt}$ oxidation reactions at both the sides. The kinetic description is coupled with a gas transport model through porous media in case of GDL, CL and channel domains.

The model is based on the following assumptions:

1. Local effects are considered along the channel direction and through the MEA, where the fluid dynamics is described in a continuous way. The differences due to gas distribution between channels and ribs are instead neglected. Indeed, the modelling

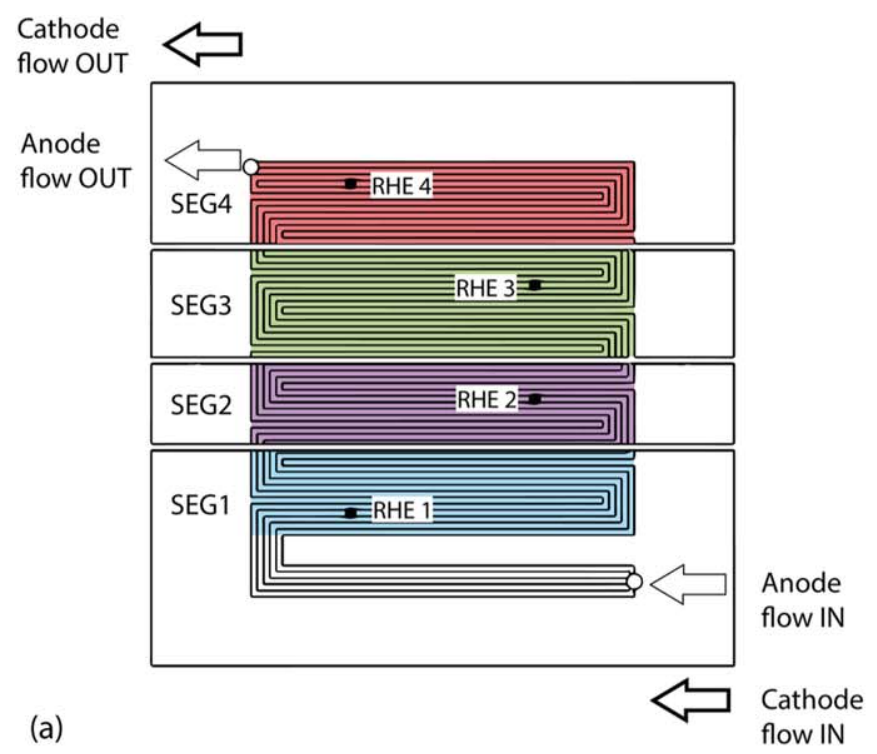

activity aims at reproducing the trends of the experimental data, for which the most relevant effects are along the channel; a good insight into the physics of the mechanisms is ensured while limiting the computational cost.

2. Liquid water transport and energy conservation are not solved, neglecting the blocking effect of liquid water and the heating of the porous media;

3. Conservation of water in the ionomer phase is not solved, thus no water crossover is considered. The ionic conductivity of both membrane and CL's is calibrated just as a temperaturedependent parameter. The assumption is considered as sufficient since all the experimental start-up and shutdown transients, against which the model was validated, were carried out at fully humidified conditions. A dedicated study about the relative humidity impact is out of the scope of the work;

4. Capacitive/pseudo-capacitive contributions are modelled by the way of a pure capacitance in case of double-layer and as a semiempirical two-step mechanism for Pt oxides reactions, at both the electrodes;

5. The direct reaction between hydrogen and oxygen catalyzed by $\mathrm{Pt}$ into the anodic compartment is limited through a calibrated parameter that represents a local maximum in the reaction rate and could be associated to the oxygen transport limitations that are locally ascribed to permeation through the ionomer ${ }^{54,55}$;

6. Hydrogen crossover is modelled as a proton/electron source generated at the membrane/cathode catalyst layer interface, as a function of the hydrogen partial pressure into the anode compartment;

7. Reaction rate associated to Pt dissolution was neglected. Its contribution is indeed negligible for the purpose of representing the in-plane currents during start-up. Other authors ${ }^{56}$ observed only few $\mathrm{pg}_{\mathrm{Pt}} \mathrm{cm}^{-2} \mathrm{~s}^{-1}$ dissolved per potential cycle, i.e. current in the range of $10^{-9} \mathrm{~A} \mathrm{~cm}^{-2}$. This order of magnitude is much lower than the other contributions; in particular, COR is approximately $10^{-3} \mathrm{~A} \mathrm{~cm}^{-2}$, as presented later in the results section.

The geometrical inputs that describe the model domain are reported in Table I. In the light of the fast transients considered in this work (computed residence time in the reference condition is $0.5 \mathrm{~s}$ ), assumption 2 and 3 are acceptable, while point 4 is fundamental for the description of processes with such short duration. A limiting reaction rate (point 5) was introduced for the

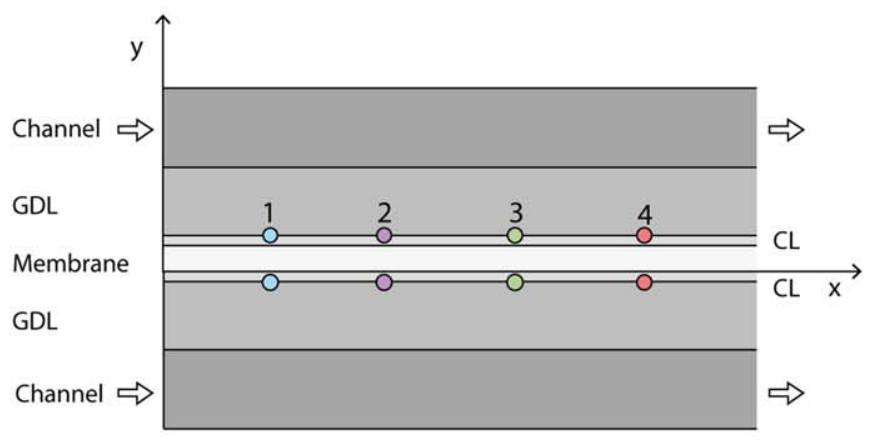

Figure 2. (a) Geometry of the flow field where the division in segments and RHE's positions are evidenced; (b) Bi-dimensional model domain (not scaled) including seven subdomains solved in the simulation, including in particular: the polymer membrane and anodic/cathodic GDL's, CL's and channels. The numbers refer to the position of the local potential probes, consistently with the experimental apparatus. $\mathrm{x}=$ in-plane direction, $\mathrm{y}=$ through-plane direction. 
Table I. Geometric parameters adopted for the model simulations.

Thicknesses were obtained from scanning electron microscope, Pt loadings are declared by the manufacturer (JMFC)

\begin{tabular}{|c|c|c|}
\hline (1) & Membrane thickness $\left(\mathrm{d}_{\mathrm{MEM}}\right)$ & $\sim 15 \mu \mathrm{m}$ \\
\hline (3) & Anode CL thickness $\left(\mathrm{d}_{\mathrm{CL}, \mathrm{A}}\right)$ & $\sim 7 \mu \mathrm{m}$ \\
\hline (2) & Cathode CL thickness $\left(\mathrm{d}_{\mathrm{CL}, \mathrm{C}}\right)$ & $\sim 10 \mu \mathrm{m}$ \\
\hline (4) & Anode Platinum loading $\left(\mathrm{L}_{\mathrm{Pt}, \mathrm{a}}\right)$ & $0.08 \mathrm{mg}_{\mathrm{Pt}} \mathrm{cm}^{-2}{ }_{\mathrm{geo}}$ \\
\hline (5) & Cathode Platinum loading $\left(\mathrm{L}_{\mathrm{Pt}, \mathrm{c}}\right)$ & $0.40 \mathrm{mg}_{\mathrm{Pt}} \mathrm{cm}^{-2}{ }_{\text {geo }}$ \\
\hline (6) & GDL thickness $\left(\mathrm{d}_{\mathrm{GDL}}\right)$ & $\sim 120 \mu \mathrm{m}$ (compressed value) \\
\hline \multicolumn{3}{|c|}{ Platinum surface areas evaluated from cyclic voltammetry (determined from the area under the hydrogen desorption region of the $\mathrm{CV}$, considering a monolayer charge density of $210 \mathrm{mC}^{-2}$} \\
\hline (7) & Anode Platinum surface area $\left(\mathrm{A}_{\mathrm{Pt}, \mathrm{a}}\right)$ & $20 \mathrm{~m}_{\mathrm{Pt}}^{2} \mathrm{~g}_{\mathrm{Pt}}^{-1}$ \\
\hline (8) & Cathode Platinum surface area $\left(\mathrm{A}_{\mathrm{Pt}, \mathrm{c}}\right)$ & $40 \mathrm{~m}_{\mathrm{Pt}}^{2} \mathrm{~g}^{-1} \mathrm{Pt}$ \\
\hline Cathode roughness factor $\left(\mathrm{rf}_{\mathrm{Pt}, \mathrm{C}}\right)$ & $160 \mathrm{~m}_{\mathrm{Pt}}^{2} \mathrm{~m}^{-2}$ geo & computed from (5) and (8) \\
\hline Anode roughness factor $\left(\mathrm{rf}_{\mathrm{Pt}, \mathrm{A}}\right)$ & $16 \mathrm{~m}_{\mathrm{Pt}}^{2} \mathrm{~m}^{-2}$ geo & computed from (4) and (7) \\
\hline Carbon roughness factor at cathode $\left(\mathrm{rf}_{\mathrm{C}, \mathrm{C}}\right)$ & $640 \mathrm{~m}^{2} \mathrm{~m}^{-2}{ }_{\mathrm{geO}}$ & assumed_-graphitized carbon \\
\hline Channel height & $0.9 \mathrm{~mm}$ & flowfield specification ${ }^{\text {a) }}$ \\
\hline Channel length & $50 \mathrm{~mm}$ & approximated \\
\hline
\end{tabular}


ORR to avoid unrealistic high local currents due to the co-existence of hydrogen and oxygen into the 2D anode catalyst layer. Its formulation is expressed by Eq. 2:

$$
\mathrm{i}_{\text {lim }}=\frac{4 F C_{O_{2, C L, \text { local }}}}{R_{M T, O_{2}}}
$$

The local oxygen transport resistance was calibrated from the limiting current test (according to a procedure similar to what described by Baker et al. ${ }^{57}$ ), performed under the same operating conditions of temperature and relative humidity of the start-up and for various oxygen concentrations, using an in-house differential hardware. ${ }^{58-60}$ The obtained value is just a proxy of the local resistance within the electrode, but the adopted approach allows a fast calibration of the parameter and the numerical stabilization of the model.

Kinetic model.-The electrochemical reactions and the reaction rates are reported in Table II, that collects also the kinetic parameters adopted in the transient model. ORR/OER, as well as PtOx reactions, are implemented at both the electrodes, COR at cathode while HOR at anode only.

The parameters were estimated, when not known from literature, exploiting the polarization curves both at $30{ }^{\circ} \mathrm{C}$ and $80{ }^{\circ} \mathrm{C}$, under fully humidified conditions, as shown in the results section. The expressions for the electrochemical reaction rates were consistent with the literature: $\mathrm{i}_{00, \mathrm{HOR}}$ and $\mathrm{E}_{\mathrm{act}, \mathrm{HOR}}$ are assumed coherently to literature review ${ }^{61} ; \mathrm{i}_{00, \mathrm{ORR}}\left(6.02 \cdot 10^{-8} \mathrm{~A} \mathrm{~cm}^{-2} \mathrm{Pt}\right.$ at $\left.80{ }^{\circ} \mathrm{C}\right)$ and $E_{\text {act,ORR }}\left(55 \mathrm{~kJ} \mathrm{~mol}^{-1}\right)$ were instead estimated from experimental data, but they are in the range of what reported by other authors. ${ }^{62}$ The exchange current densities of HOR, ORR/OER and COR under actual conditions were computed from: the $\mathrm{i}_{00}$ at reference conditions, from an Arrhenius term that describes temperature effects and from a concentration-dependent quantity. This last term corresponds to the activity value of the oxidized/reduced species $\left(a_{i}^{\gamma}\right)$, that could be rewritten as the ratio between the actual partial pressure of the species and the reference pressure of $101.325 \mathrm{kPa}\left(\frac{p_{i}}{p_{i, \text { ref }}}\right)$. The reaction order $\gamma$ was set equal to 1 for both HOR and ORR. Such choice made the model more stable, ensuring anyway a good agreement with the experimental results of polarization curves. For water, activity assumes a unitary value.

A simple, one-step kinetic expression was adopted for COR in this work. In reality, carbon oxidation may result from the interplay of surface oxide formation on carbon and platinum, ${ }^{63,64}$ being in some extent catalyzed; however, further insights are out of the scope of the present study.

For COR kinetic parameters, there is not a general consensus in literature: exchange current density and charge transfer coefficient differ, even of order of magnitudes. Gu et al. reported values of $1.03 \cdot 10^{-18} \mathrm{~A} \mathrm{~cm}_{\mathrm{C}}{ }^{2}$ and 0.67 respectively, ${ }^{14}$ Maranzana et al. values of $10^{-28} \mathrm{~A} \mathrm{~cm}^{-2} / 10^{-8} \mathrm{~A} \mathrm{~cm}^{-2}$ and $1 / 0.6$ for catalyzed/not catalyzed carbon oxidation at $80{ }^{\circ} \mathrm{C}^{16}$ On the other hand, other authors considered a much lower charge transfer coefficient: Meyers and Darling estimated it should be $0.275,{ }^{13}$ Mathias et al. $0.477,{ }^{65}$ Mittermeier et al. 0.362. ${ }^{36}$ The charge transfer coefficient reduction is partly compensated by a larger exchange current density (e.g. $\left.2.8 \cdot 10^{-13} \mathrm{~A} \mathrm{~cm}^{-2} \mathrm{C}^{36}\right)$. Here, cyclic voltammetry (CV) with a potential window up to $1.6 \mathrm{~V}$ are utilized in order to quantify these parameters. Since it ensured a better description of the experimental data, among all the available references $\boldsymbol{\alpha}_{\mathrm{COR}}$ was set equivalent to 0.362 . Exchange current density was calibrated instead, resulting in $\approx 5 \cdot 10^{-12} \mathrm{~A} \mathrm{~cm}^{-2} \mathrm{C}$ at $80{ }^{\circ} \mathrm{C}$. CV's at different temperatures permitted to estimate the activation energy as reported in Table II, that is coherent to other literature data. ${ }^{4,65}$

Finally, the capacitive/pseudo-capacitive model involves: $(i)$ the introduction of a pure capacitance to describe those currents due to the charge/discharge of the double-layer, in accordance with Eq. 3 (ii) a semi-empirical two-steps mechanism for Pt oxidation, as described below.

$$
i_{d l}=C_{d l, A / C} \frac{d\left(\varphi_{s}-\varphi_{l}\right)}{d t}
$$

Many researchers attempted to simulate voltammetry to gain a better understanding of the platinum oxides reactions. Each study is able to replicate some features, but none have achieved the correct shape and behavior of CV's over a wide range of operating conditions. PtOx reactions were investigated and the compromise between consistency with the experiments and number of unknown parameters led to the definition of the model described by Eqs. 4 and 5. On one hand, it was necessary a good description of the most relevant CV's features, as described in the results section. On the other hand, a too complex sub-model should be avoided, otherwise its implementation in the 2D start-up/shut-down transient would end with not acceptable computational costs.

$$
\begin{gathered}
\mathrm{Pt}+\mathrm{H}_{2} \mathrm{O} \leftrightarrows \mathrm{PtOH}+\mathrm{H}^{+}+e^{-} \\
\mathrm{PtOH} \leftrightarrows \mathrm{PtO}+\mathrm{H}^{+}+e^{-}
\end{gathered}
$$

The kinetics of the reactions are described by Eqs. 6 and 7. Their formulation recalls the works of Conway ${ }^{66}$ and Darling and Meyers ${ }^{67}$ :

$$
\begin{aligned}
i_{P t O H}= & i_{00, P t O H} \cdot \exp \left(-\frac{E_{P t O H}^{a c t}}{R T} \cdot\left(1-\frac{T}{T_{r e f}}\right)\right) \\
& \cdot \exp \left(-\frac{\omega_{P t O H} \Theta_{P t O H}}{R T}\right) \cdot \exp \left(\frac{\alpha_{P t O H} F}{R T} \cdot \eta_{P t O H}\right) \\
& -\Theta_{P t O H} \cdot \exp \left(-\frac{\left(1-\alpha_{P t O H}\right) F}{R T} \cdot \eta_{P t O H}\right) \\
i_{P t O}= & i_{00, P t O} \cdot \exp \left(-\frac{E_{P t O}^{a c t}}{R T} \cdot\left(1-\frac{T}{T_{r e f}}\right)\right) \cdot \Theta_{P t O H} \\
& \cdot \exp \left(-\frac{\left.\omega_{P t O} \Theta_{P t O}\right) \cdot \exp \left(\frac{\alpha_{P t O} F}{R T} \cdot \eta_{P t O}\right)}{R T}\right. \\
& -\Theta_{P t O} \cdot \exp \left(-\frac{\left(1-\alpha_{P t O}\right) F}{R T} \cdot \eta_{P t O}\right)
\end{aligned}
$$

The platinum oxide coverage mass balances are expressed through the differential Eqs. 8 and 9:

$$
\begin{gathered}
\frac{d \Theta_{P t O H}}{d t}=\frac{i_{P t O H}}{N_{P t} F}-\frac{i_{P t O}}{N_{P t} F} \\
\frac{d \Theta_{P t O}}{d t}=\frac{i_{P t O}}{N_{P t} F}
\end{gathered}
$$

Where the maximum surface coverage $\mathrm{N}_{\mathrm{Pt}}$ is given by Eq. 10:

$$
N_{P t}\left[\frac{m o l}{m_{\text {geo }}^{3}}\right]=\frac{2.1\left[\frac{C}{m_{P t}^{2}}\right] \cdot r f_{P t, C / A}\left[\frac{m_{P t}^{2}}{m_{g e o}^{2}}\right]}{d_{C L, C / A}[m] \cdot F\left[\frac{C}{m o l}\right]}
$$

The kinetics were calibrated on a large set of cyclic voltammetry measurements, performed in a wide range of operating conditions. This set of cyclic voltammetry data included a sensitivity analysis on the upper potential limit, studied in the range from $0.7 \mathrm{~V}$ to $1.6 \mathrm{~V}$, and operating temperature, investigated at $30,40,60$ and $80{ }^{\circ} \mathrm{C}$; it was used for the calibration of the kinetic equations. Calibration was also performed with different holding time simulations, by the way of reproducing the PtOx reduction current peak (Fig. SI-1 available 
Table II. Kinetic equations and parameters.

HOR electrode current

ORR electrode current

OER electrode current

COR electrode current

Surface overpotential for reaction $\mathrm{j}$

Reversible potential for reaction $\mathrm{j}$

Introduction of limiting current for ORR

HOR

$\mathrm{i}_{00, \mathrm{HOR}}$

$\mathrm{E}_{\text {act,HOR }}$

$\mathrm{E}^{\mathrm{OC}} \mathrm{HOR}$

$\Delta \mathrm{E}_{\mathrm{HOR}}$

ORR

$\mathrm{i}_{00, \mathrm{ORR}}$

$\mathrm{E}_{\text {act, ORR }}$

$\mathrm{E}$ OR

$\Delta \mathrm{E}_{\mathrm{ORR}}$

$\alpha_{\mathrm{ORR}}$

$\mathrm{R}_{\mathrm{MT}, \mathrm{O} 2,30 \mathrm{C}}$

$\mathrm{R}_{\mathrm{MT}, \mathrm{O} 2,80 \mathrm{C}}$

OER

$\mathrm{i}_{00, \mathrm{OER}}$

$\mathrm{E}_{\text {act, OER }}$

$\triangle \mathrm{E}_{\mathrm{OER}}$

$\alpha_{\mathrm{OER}}$

COR

$\mathrm{E}_{\text {act, }, \mathrm{COR}}$

$\mathrm{E}^{\mathrm{O} 0} \mathrm{COR}_{\mathrm{CO}}$

$\Delta \mathrm{E}_{\mathrm{COR}}$
$i_{H O R}=i_{00, H O R} \cdot r f_{P t, A} \cdot\left(\frac{p_{H 2}}{p_{H 2, r e f}}\right) \cdot \exp \left(-\frac{E_{H O R}^{a c t}}{R T} \cdot\left(1-\frac{T}{T_{r e f}}\right)\right) \cdot \frac{2 F}{R T} \cdot \eta_{H O R}$

$i_{\text {ORR }}=i_{00, O R R}$.

$r f_{P t, A / C}$.

$$
\begin{aligned}
& \left(\frac{p_{O 2}}{p_{O 2, \text { ref }}}\right) \\
& \exp \left(-\frac{E_{O R R}^{a c t}}{R T}\right. \\
& \left.\left(1-\frac{T}{T_{\text {ref }}}\right)\right) \\
& \exp \left(-\frac{\alpha_{O R R} F}{R T} .\right.
\end{aligned}
$$

$\left.\eta_{\text {ORR }}\right)$

$i_{O E R}=i_{00, O E R} \cdot r f_{P t, A / C} \cdot \exp \left(-\frac{E_{O E R}^{a c t}}{R T} \cdot\left(1-\frac{T}{T_{r e f}}\right)\right) \exp \left(\frac{\alpha_{O E R} F}{R T} \cdot \eta_{O E R}\right)$

$i_{C O R}=i_{00, C O R} \cdot r f_{C, C} \cdot \exp \left(-\frac{E_{C O R}^{a c t}}{R T} \cdot\left(1-\frac{T}{T_{r e f}}\right)\right) \cdot \exp \left(\frac{\alpha_{C O R} F}{R T} \cdot \eta_{C O R}\right)$

$\eta_{j}=\Phi_{s}-\Phi_{l}-E_{j}^{0}$

$E_{j}^{0}=E_{j}^{00}+\Delta E_{j} \cdot(T-298.15 K)+\frac{R T}{n F} \ln \left(\frac{\Pi\left(a_{o}\right)^{v_{o}}}{\prod\left(a_{r}\right)^{v_{r}}}\right)$

$i_{O R R}^{*}=\frac{i_{O R R}}{1+\frac{i O R R}{i_{l i m}}}$

Activation energy

Potential temperature coefficient

Exchange current density at $30{ }^{\circ} \mathrm{C}$

Activation energy

Standard Electrode Potential (at $25^{\circ} \mathrm{C}$ )

Potential temperature coefficient

Oxygen mass transport resistance at $30^{\circ} \mathrm{C}$

Oxygen mass transport resistance at $80{ }^{\circ} \mathrm{C}$

Exchange current density at $30{ }^{\circ} \mathrm{C}$

Activation energy

Standard Electrode Potential (at $25^{\circ} \mathrm{C}$ )

Potential temperature coefficient
Exchange current density at $30{ }^{\circ} \mathrm{C}$

Standard Electrode Potential (at $25^{\circ} \mathrm{C}$ )

Cathodic transfer coefficient

Cathodic transfer coefficient

$0.17 \mathrm{~A} \mathrm{~cm}^{-2}$

$10 \mathrm{~kJ} \mathrm{~mol}^{-1}$

$0 \mathrm{~V}$

$0 \mathrm{~V} \mathrm{~K}^{-1}$

$2.71 \cdot 10^{-9} \mathrm{~A} \mathrm{~cm}^{-2}$

$55 \mathrm{~kJ} \mathrm{~mol}^{-1}$

$1.23 \mathrm{~V}$

$-9 \cdot 10^{-4} \mathrm{~V} \mathrm{~K}^{-1}$

0.98

$0.52 \mathrm{~s} \mathrm{~cm}^{-1}$

$0.40 \mathrm{~s} \mathrm{~cm}^{-1}$

$2.22 \cdot 10^{-10} \mathrm{~A} \mathrm{~cm}^{-2}$

$38 \mathrm{~kJ} \mathrm{~mol}^{-1}$

$1.23 \mathrm{~V}$

$-9 \cdot 10^{-4} \mathrm{~V} \mathrm{~K}^{-1}$

0.65

$6.43 \cdot 10^{-14} \mathrm{~A} \mathrm{~cm}^{-2}$

$76.7 \mathrm{~kJ} \mathrm{~mol}^{-1}$

$0.207 \mathrm{~V}$

$-8.5 \cdot 10^{-4} \mathrm{~V} \mathrm{~K}^{-1}$

assumed

assumed

typical

typical

estimated (polarization curves) estimated (polarization curves)

typical

typical

estimated (polarization curves)

estimated (limiting current test) estimated (limiting current test)

assumed $^{36}$

assumed $^{36}$

typical

typical

assumed $^{36}$

Exchange current density at $30{ }^{\circ} \mathrm{C}$

Standard Electrode Potential (at $25^{\circ} \mathrm{C}$ )

Potential temperature coefficient estimated (voltammetry) estimated (voltammetry) typical $^{15} 4$

typical $^{15}$ 


\section{Table II. (Continued).}

$\alpha_{\mathrm{COR}}$

PtOx reactions

$\mathrm{i}_{00, \mathrm{Pt}, \mathrm{PtOH}}$

$\mathrm{i}_{\mathrm{OO}, \mathrm{PtOH}, \mathrm{PtO}}$

$\mathrm{E}_{\mathrm{act}, \mathrm{Pt}, \mathrm{PtOH}}$

$\mathrm{E}_{\mathrm{act}, \mathrm{PtOH}, \mathrm{PtO}}$

$\mathrm{E}^{00}{ }_{\mathrm{Pt}, \mathrm{PtOH}}$

$\mathrm{E}^{00} \mathrm{PtOH}, \mathrm{PtO}$

$\alpha_{\mathrm{Pt}, \mathrm{PtOH}}$

$\alpha_{\mathrm{PtOH}, \mathrm{PtO}}$
Anodic transfer coefficient

Exchange current density at $30{ }^{\circ} \mathrm{C}$

Exchange current density at $30{ }^{\circ} \mathrm{C}$

Activation energy

Activation energy

Standard Electrode Potential (at $25^{\circ} \mathrm{C}$ )

Standard Electrode Potential $\left(\right.$ at $\left.25^{\circ} \mathrm{C}\right)$

Anodic transfer coefficient (voltammetry \& holding tests)

Anodic transfer coefficient (voltammetry \& holding tests)

\begin{tabular}{|c|c|}
\hline 0.362 & assumed $^{37}$ \\
\hline $\begin{array}{l}1.1258 \\
.10^{-4} \mathrm{~A} \mathrm{~cm}^{-2}\end{array}$ & $\begin{array}{l}\text { estimated (voltammetry \& holding } \\
\text { tests) }\end{array}$ \\
\hline $8.87 \cdot 10^{-9} \mathrm{~A} \mathrm{~cm}^{-2}$ & $\begin{array}{l}\text { estimated (voltammetry \& holding } \\
\text { tests) }\end{array}$ \\
\hline $2.67 \mathrm{~kJ} \mathrm{~mol}^{-1}$ & $\begin{array}{l}\text { estimated (voltammetry \& holding } \\
\text { tests) }\end{array}$ \\
\hline $94.83 \mathrm{~kJ} \mathrm{~mol}^{-1}$ & $\begin{array}{l}\text { estimated (voltammetry \& holding } \\
\text { tests) }\end{array}$ \\
\hline $0.7619 \mathrm{~V}$ & $\begin{array}{l}\text { estimated (voltammetry \& holding } \\
\text { tests) }\end{array}$ \\
\hline $1.0025 \mathrm{~V}$ & $\begin{array}{l}\text { estimated (voltammetry \& holding } \\
\text { tests) }\end{array}$ \\
\hline 0.7076 & estimated \\
\hline
\end{tabular}

0.3562

estimated 
online at stacks.iop.org/JES/168/054508/mmedia). An additional analysis was performed to simulate the effect of the scan rate in the cyclic voltammetry: the model was validated on CV's for which the scan rate was varied from 125 to $1000 \mathrm{mV} \mathrm{s}^{-1}$ and this test was repeated at both $30^{\circ} \mathrm{C}$ and $80{ }^{\circ} \mathrm{C}$. The results are presented later.

Mass and charge conservation equations.-In the model domain depicted in Fig. 2 mass conservation in gas phase is solved in all media both at anode and cathode but for the polymer membrane, distinguishing between channel and porous media. The mass and momentum balance of the Brinkman Equations are solved for porous media (GDL and CL) and Navier-Stokes equations for the channels:

$$
\frac{\partial\left(\varepsilon_{i} \rho\right)}{\partial t}+\nabla \cdot(\rho \boldsymbol{u})=Q_{m}
$$

$<\mathrm{Z}$

$$
\begin{gathered}
\frac{\rho}{\varepsilon_{i}}\left(\frac{\partial u}{\partial t}+(\boldsymbol{u} \cdot \nabla) \frac{\boldsymbol{u}}{\varepsilon_{i}}\right)=\nabla \cdot\left[-\mathrm{p} \mathbf{I}+\frac{\mu}{\varepsilon_{i}}\left(\nabla \boldsymbol{u}+(\nabla \boldsymbol{u})^{T}\right)\right. \\
\left.-\frac{2 \mu}{3 \varepsilon_{i}}(\nabla \cdot \boldsymbol{u}) \mathbf{I}\right]-\left(\mu k_{i}^{-1}+\frac{Q_{m}}{\varepsilon_{i}^{2}}\right) \boldsymbol{u}
\end{gathered}
$$

At the channel side next to the GDL the continuity of velocity, pressure and species concentration is ensured. The mass conservation equation for each species $j$ is guaranteed through Eq. 13 and the Fick's law of diffusion considered, as expressed by Eq. 14:

$$
\begin{gathered}
\varepsilon_{i} \rho \frac{\partial\left(\omega_{j}\right)}{\partial t}+\nabla \cdot \boldsymbol{j}_{j}+\rho(\boldsymbol{u} \cdot \nabla) \omega_{j}=R_{j} \\
\boldsymbol{j}_{j}=-\left(\rho D_{j}^{F} \frac{\varepsilon_{i}}{\tau_{i}} \cdot \nabla \omega_{j}+\rho \omega_{j} D_{j}^{F} \frac{\varepsilon_{i}}{\tau_{i}} \frac{\nabla M_{n}}{M_{n}}\right)
\end{gathered}
$$

Where $\mathrm{R}_{\mathrm{j}}$ is the reaction rate of the $j$ th species per unit volume, computed as $R_{j}=-M_{w, j} \cdot \sum_{m} \frac{v_{j, m} i_{v, m}}{n_{m} F}$; each $m$ reaction, with $v_{\mathrm{j}, \mathrm{m}}$ stoichiometric coefficients, involves $\mathrm{n}_{\mathrm{m}}$ participating electrons and generates a local volumetric current density $i_{\mathrm{v}, \mathrm{m}}$. $\mathrm{Q}_{\mathrm{m}}$ is the total mass source derived from the summation of each net source $\mathrm{R}_{\mathrm{j}} \cdot \varepsilon_{\mathrm{i}}$ is the porosity, $\tau_{\mathrm{i}}$ is the tortuosity and $\mathrm{k}_{\mathrm{i}}$ the permeability of the medium $i$. $D_{j}^{F}$ indicates the diffusivity: $D_{j}^{F}=D_{j, r e f}^{F} \cdot\left(\frac{T}{T_{r e f}}\right)^{1.5}, \omega_{j}$ the mass fraction, $M_{w, j}$ the relative molar mass. For channels, $\mathbf{R}_{\mathbf{j}}=0, \varepsilon_{\mathbf{i}}=\tau_{\mathbf{i}}$ $=1, \mathrm{k}_{\mathrm{i}} \rightarrow+\infty$.

Electron charge conservation in both GDL and CL is coupled with the Ohm's law to solve the scalar electric potential field:

$$
\begin{gathered}
\nabla \cdot \mathrm{i}_{s}=-\sum_{m} i_{v, m} \\
i_{s, G D L / C L}=-\sigma_{s, G D L / C L} \nabla \varphi_{s}
\end{gathered}
$$

The Eq. 15 is set to zero in case of GDL, since no reactions are occurring. The membrane is instead assumed as a perfect electronic insulator. In analogy, both in the membrane and in the CL's, the electrolyte potential is simulated combining Ohm's law and charge conservation:

$$
\begin{gathered}
\nabla \cdot \mathrm{i}_{l}=\sum_{m} i_{v, m} \\
i_{l, M E M / C L}=-\sigma_{l} \cdot M_{l, M E M / C L} \cdot \nabla \varphi_{l}
\end{gathered}
$$

Where $M_{l}$ is used to account for the different ionomer content in the membrane and in the catalyst layer. The transfer parameters are summarized in Table III. Note that GDL electrical conductivity is some order of magnitudes higher than the typical values for this component: this fictitious parameter resembles the flowfield behaviour in the experimental setup, which ensures an almost uniform potential $\phi_{s}$ for the MEA along the in-plane direction: differences of few $\mathrm{mV}$ only are detected. Model parameters collected in Table III, like diffusivities and GDL/CL properties, have been assumed referring to literature ${ }^{68,69}$ and checked comparing the cell performance.

Boundary conditions. - The boundary conditions in the 2D model were set consistently with the experiments. The gas inlet is placed at the left boundary, where the mass flow and its composition are imposed. The outlet is set as the right boundary, where the outlet pressure is constrained. All other boundaries are simulated with zero flux for both mass and charge.

Simulation of start-up.-The solving process is based on finding a first stationary convergent solution. The air/air initial state, with fully developed flows, is determined by imposing the local potential equivalent to $1.05 \mathrm{~V}$ for both anode and cathode, as derived from experiments. This approach permits to identify an adequate surface coverage. Then, for the transient problem, the inflow composition is described as a time-dependent parameter by the way of a step function, smoothen through a transition zone of $0.01 \mathrm{~s}$. Mixture specification switches from air to hydrogen at $0.1 \mathrm{~s}$ in case of startup, or vice-versa if shut-down is simulated. In addition, at the inlet section the standard flow rate was imposed. Since the channel length $L$ of the simulations is shorter than the real case, a corrective factor of $9.26 \cdot 10^{-2}$ was introduced for the flow rate, as well as a factor of one third, because the model deals with a single channel with respect to the triple serpentine experimental hardware. These corrections made the residence time of the simulated process equivalent to the theoretical residence time of the experiments.

Numerical implementation.-The description of the numerical implementation is here discussed in detail because the problem is stiff and complex to solve numerically, so the optimization of the solver required a large effort to achieve a stable and reasonably fast solution procedure. A rectilinear grid mapped mesh was used, regularly distributed along the channel direction while finer going in the through cell direction, from the channel to the polymeric membrane. This choice ensured a proper discretization of the thin catalyst layers in particular at the anode side, where the co-existence of the reacting species is more difficult to be modelled. In the $x$ direction, the mesh grid was divided into 4.L elements. On the $y$ direction, channels were divided in 20 parts, GDL's in 15 and both the catalyst layers and the membrane in 10 elements. The model is based on the secondary current distribution module and on the reacting flow in porous electrode module. The initial stationary problem and each time step of the transient problem are solved using a fully coupled method with direct MUMPS solver. The timedependent study uses a strict BDF method for the time stepping, with a maximum step of $0.001 \mathrm{~s}$. Highly nonlinear Newton method was adopted, with a damping factor in the range of $1 \mathrm{e}-8 / 1 \mathrm{e}-4$, while the termination criterion was based either on tolerance or iterations, fixed at a maximum of 30 .

\section{Results and Discussion}

Figure 3 shows the results given by the model after the calibration process, that was based on differential cell data. The purpose of the differential cell is to minimize the influence from the testing hardware on results of performance. ${ }^{59,60}$ The material properties, as relevant kinetics and transport parameters (Tables II and III), were therefore calibrated without any interdependence, like the flowfield design; through this setup, it was aimed attention at the MEA characteristics only. Figure 3a compares the MEA actual performance with the model output at relevant conditions for the start-up, i.e. 30 and $80{ }^{\circ} \mathrm{C}$. Figure $3 \mathrm{~b}$ shows the simulation of the cyclic voltammetry against the measured one, in which the $\mathrm{Pt}$ 
Table III. Model parameters related to mass and charge conservation equations.

\begin{tabular}{|c|c|c|c|}
\hline $\mathrm{C}_{\mathrm{dl}, \mathrm{c}}$ & Cathode double-layer capacitance & $0.0458 \mathrm{~F} \mathrm{~cm}^{-2}$ & fit (voltammetry) \\
\hline $\mathrm{C}_{\mathrm{d} l, \mathrm{a}}$ & Anode double-layer capacitance & $0.0150 \mathrm{~F} \mathrm{~cm}^{-2}$ & fit (voltammetry) \\
\hline $\mathrm{D}_{\mathrm{H} 2}$ & Hydrogen diffusion coefficient at $80{ }^{\circ} \mathrm{C}$ & $1.24 \cdot 10^{-5} \mathrm{~m}^{2} \mathrm{~s}^{-1}$ & typical $^{70}$ \\
\hline $\mathrm{D}_{\mathrm{O} 2}$ & Oxygen diffusion coefficient at $80{ }^{\circ} \mathrm{C}$ & $0.28 \cdot 10^{-5} \mathrm{~m}^{2} \mathrm{~s}^{-1}$ & typical $^{70}$ \\
\hline $\mathrm{D}_{\mathrm{N} 2}$ & Nitrogen diffusion coefficient at $80^{\circ} \mathrm{C}$ & $1.24 \cdot 10^{-5} \mathrm{~m}^{2} \mathrm{~s}^{-1}$ & typical $^{70}$ \\
\hline $\mathrm{D}_{\mathrm{H} 2 \mathrm{O},(1)}$ & Water diffusion coefficient at $80{ }^{\circ} \mathrm{C}$, in air & $0.36 \cdot 10^{-5} \mathrm{~m}^{2} \mathrm{~s}^{-1}$ & typical $^{70}$ \\
\hline $\mathrm{D}_{\mathrm{H} 2 \mathrm{O},(2)}$ & Water diffusion coefficient at $80{ }^{\circ} \mathrm{C}$, in $\mathrm{H}_{2}$ & $1.24 \cdot 10^{-5} \mathrm{~m}^{2} \mathrm{~s}^{-1}$ & typical $^{70}$ \\
\hline$\tau_{\mathrm{GDL}}$ & GDL tortuosity & 4 & assumed \\
\hline$\tau_{\mathrm{CL}}$ & Electrode tortuosity & 9 & assumed \\
\hline$\varepsilon_{\mathrm{GDL}}$ & GDL porosity & 0.47 & assumed \\
\hline$\varepsilon_{\mathrm{CL}}$ & Electrode porosity & 0.32 & assumed \\
\hline$\sigma_{\mathrm{s}, \mathrm{GDL}}$ & GDL electrical conductivity & $1 \cdot 10^{4} \mathrm{~S} \mathrm{~cm}^{-1}$ & assumed \\
\hline$\sigma_{\mathrm{s}, \mathrm{CL}}$ & Electrode electrical conductivity & $1 \mathrm{~S} \mathrm{~cm}^{-1}$ & typical \\
\hline$\sigma_{1,0}$ & Proton conductivity at $30^{\circ} \mathrm{C}$ & $7.8 \mathrm{~S} \mathrm{~m}^{-1}$ & $\begin{array}{l}\text { estimated (polarization } \\
\text { curves) }\end{array}$ \\
\hline $\mathrm{M}_{1, \mathrm{MEM}}$ & Microstructure factor of membrane ionomer & 1 & typical \\
\hline $\mathrm{M}_{1, \mathrm{CL}}$ & Microstructure factor of electrode ionomer & 0.15 & assumed $^{68}$ \\
\hline $\mathrm{E}_{\mathrm{act}, \sigma}$ & Energy activation for proton conductivity & $15 \mathrm{~kJ} \mathrm{~mol}^{-1}$ & assumed $^{68}$ \\
\hline
\end{tabular}
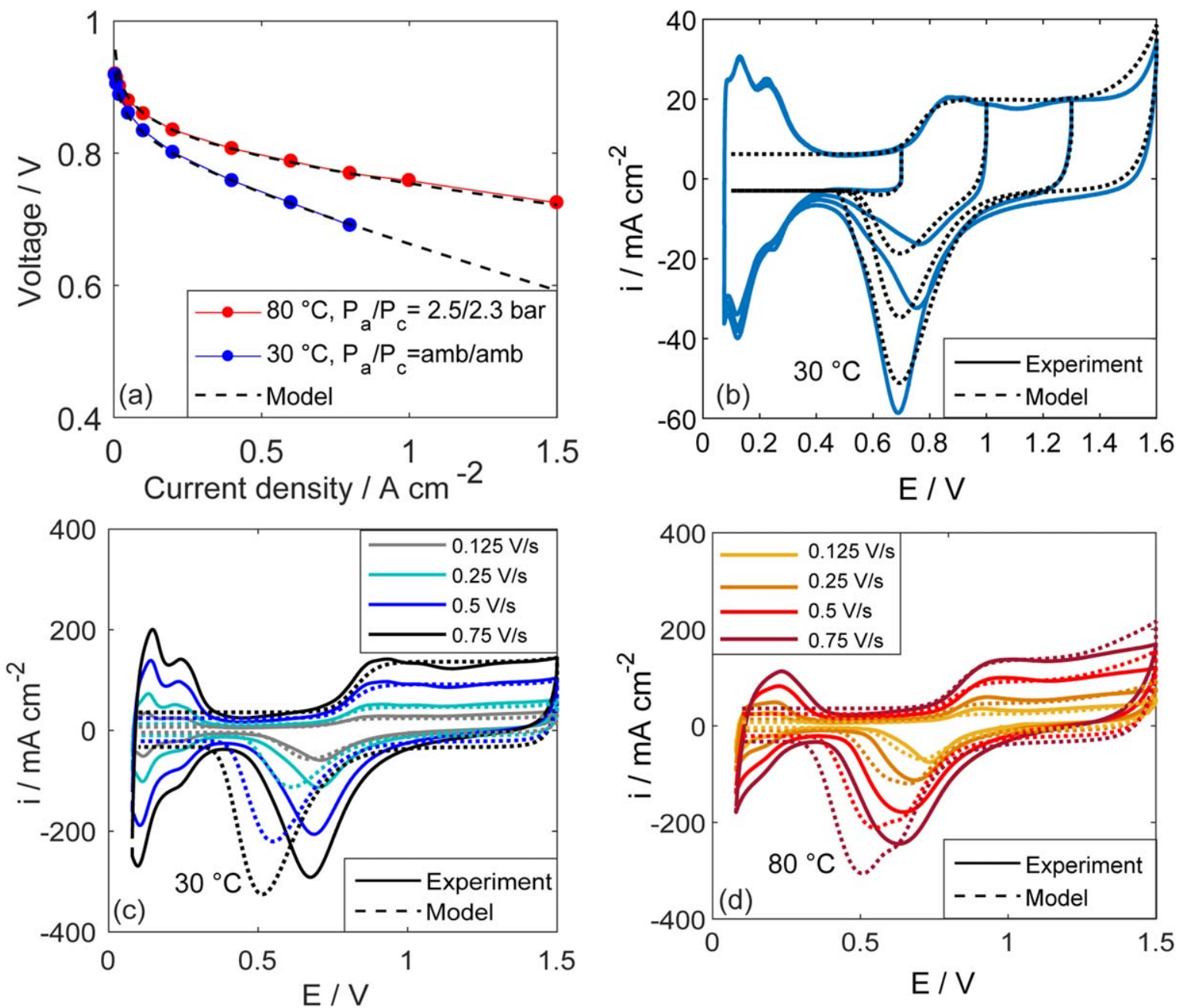

Figure 3. Specific measurements (solid lines) performed for the calibration and validation of unknown parameters and comparison with model simulations (dotted lines): (a) polarization curves performed on differential cell hardware in conditions: (red curve) $\mathrm{T}_{\text {cell }}=80{ }^{\circ} \mathrm{C}$, fully humidified reactants $\left(80{ }^{\circ} \mathrm{C}\right.$ dew point) at $\mathrm{P}_{\mathrm{A}, \text { in }} / \mathrm{P}_{\mathrm{C}, \text { in }}=2.3 / 2.5$ bar and $\lambda_{\mathrm{A}} / \lambda_{\mathrm{C}}=8 / 10$; (blue curve) $\mathrm{T}_{\text {cell }}=30^{\circ} \mathrm{C}$, fully humidified reactants $\left(30^{\circ} \mathrm{C}\right.$ dew point $)$ at $\mathrm{P}_{\mathrm{A}, \text { out }} / \mathrm{P}_{\mathrm{C}, \text { out }}=$ atm $/$ atm and $\lambda_{\mathrm{A}} / \lambda_{\mathrm{C}}$ $=8 / 10$ (b) effect of upper potential in cyclic voltammetry measurements performed in the range $1.0 \mathrm{~V}-1.6 \mathrm{~V}$ at $30^{\circ} \mathrm{C}$ and scan rate of $50 \mathrm{mV} \mathrm{s}{ }^{-1}$; (c) effect of scan rate in cyclic voltammetry measurements performed in the range $125 \mathrm{mV} \mathrm{s}^{-1}-750 \mathrm{mV} \mathrm{s}^{-1}$ at $30{ }^{\circ} \mathrm{C}$ (d) effect of scan rate in cyclic voltammetry measurements performed in the range $125 \mathrm{mV} \mathrm{s}^{-1}-750 \mathrm{mV} \mathrm{s}^{-1}$ at $80^{\circ} \mathrm{C}$. 
The main features that are correctly reproduced are: the anodic peak around $0.8 \mathrm{~V}$, the immediately following broad plateau, the cathodic peak current and the irreversible oxidation occurring at high potential and attributed to COR. Figures $3 \mathrm{c}$ and $3 \mathrm{~d}$ report how the cyclic voltammetry features change under different scan rates and cell temperature conditions. The analysis of CV's at high scan-rates allow to reproduce a dynamic that is closer to very fast start-up processes reported in this work and, generally speaking, of realistic starts and stops. This is a crucial point to investigate. About this topic, literature review ${ }^{71,72}$ evidenced that reproducing CV's over a wide range of scan rates is a difficult task, that requires to include more accurate and multistep mechanisms for the oxides growth. The presented model is a compromise, in order to acceptably reproduce the main features of cyclic voltammetry, even in case of rapid transients, while keeping acceptable computational cost when integrated in the start-up/shutdown simulation. In particular, the increase of the scan rate value causes a shift in the reduction peak and a change of its shape, a trend that is captured by the model, even if more emphasized.

Start-up in the reference condition.-D During a start-up, the fuelfilled part operates regularly as a power supply ("active region") and polarizes the oxidant-filled part ("passive region") that operates as an electrolysis cell. In the following, the terms anode and cathode will be improperly used to indicate the two sides of the MEA referring to normal active operation, independently of the reactions occurring. A simplified representation of the reactions in each region is schematized in Fig. 4. As a result of this heterogeneous situation, an internal current compensates the simultaneous generation and consumption of charge occurring at different positions along the same electrode, in dependence on the hydrogen/air front location. In other words, the reverse proton flow in the air/air and in the hydrogen/air regions leads to a circular current flow in the cell.

After the successful calibration of the unknown parameters in the model, an air start is simulated and the results compared to the experimental data in Fig. 5: Figs. 5a and 5b show the local electrode potential measured and simulated in the positions highlighted in Fig. 2, while in Figs. 5c and 5d the local in-plane currents drawn in each segment are plotted for model and experiment respectively. A good consistency between model and experiment is generally observed. At each time step, the MEA is divided in two regions of different area: in the "active region," a negative current and a low cathode potential are observed $(<1 \mathrm{~V})$, while in the "passive region," a positive current and a high cathode potential are reported $(>1 \mathrm{~V})$. As hydrogen is supplied, the HOR taking place makes the first segment an active region having a negative current, as depicted in Fig. 5c. The other segments $(2,3,4)$ behave as passive regions, until hydrogen arrives in their sections: this occurs when their associated current evolves from positive to negative. Coherently to the current measurements, local RHE's show an increase in the cathodic potential when the MEA portion behaves passively: the $4^{\text {th }}$ RHE reaches potentials as high as $1.6 \mathrm{~V}$, a value that becomes even higher $(\approx 1.7 \mathrm{~V})$ for the very outlet section, which value is available from the simulation, represented by the black line in Fig. 5a. Then, potential values fall to those typical for PEMFC operations when the MEA region switches to an active functioning. The anode potential moves instead from the open circuit potential when exposed to air flow $(\approx 1.05 \mathrm{~V})$, to the hydrogen equilibrium potential $(0 \mathrm{~V})$. The open circuit potential under air is found to be different from theoretical equilibrium value expected for ORR both in model and experiment, and this effect is attributed to the presence of Pt surface oxidation parasitic reactions.

For each segment, the model permits to quantify the contribution of the specific reaction to the overall current as the start-up process evolves. Figures $6 \mathrm{a}$ and $6 \mathrm{~b}$ show the share of each electrochemical reaction for the $4^{\text {th }}$ segment. When the derivative of electrode potential in time is high, the capacitive current is dominant. This is found, for example, at the very beginning of the transient: the initial sudden change in local anode (dashed lines) and cathode (full lines)

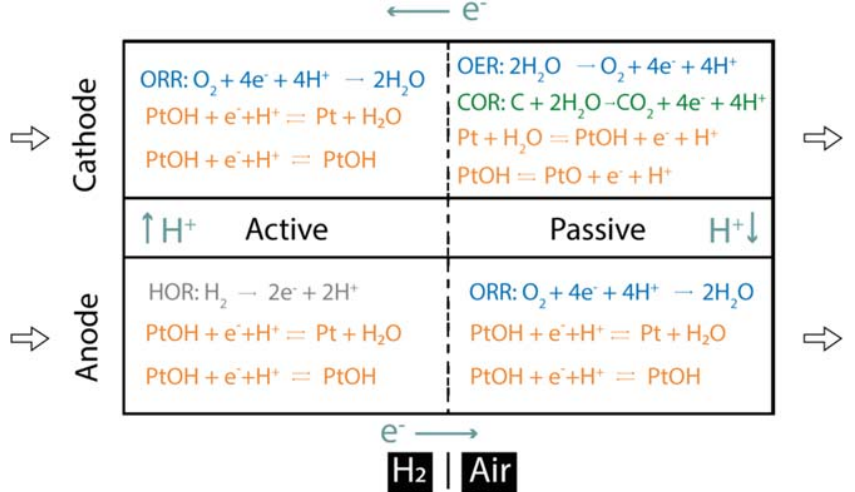

Figure 4. Schematic of the reverse-decay reactions and current flow that occur during a start-up.

potentials, visible in Figs. 5a and 5b, is linked to the current peak due to double-layers. Immediately after, as the cathode potential rises, Pt oxide formation becomes the major contributor at cathode. Carbon oxidation reaction contributes significantly only when potential values get as high as $1.5 \mathrm{~V}$ and it weights even most when the voltage profile rapidly goes down. Indeed, a process of redistribution of charges occurs as the front of hydrogen has passed. Charge redistribution is due to a homogenization of the catalyst layer in terms of Pt oxides, as first observed by Lamibrac et al. ${ }^{46}$ The air removal at anode forces the potentials down such fast to make the cathodic PtOx contributions fade and the cathodic double-layer a driving force for the support oxidation. In literature, pseudocapacitive contributions for the cathode electrode have been widely recognized as positive for the mitigation of carbon corrosion. ${ }^{14}$ However, it is observed here that an increase of the cathode doublelayer capacitance could incentive COR close to the transient end, when potentials start to go down.

The total charge for the segment $j$ and related to a specific $m$ reaction, is computed according to Eq. 19, over the complete transient:

$$
\text { Charge }_{m, s e g j}=\int i_{m, s e g j} d t
$$

Figure $6 \mathrm{c}$ collects the single-reaction charges for cathode. As clearly visible, cathodic Pt oxidation reactions play a crucial role for the $75 \%$ of the MEA area. For the $4^{\text {th }}$ segment, where the carbon corrosion is promoted most, the PtOx charge is $\approx 20$ times the COR charge. These results demonstrate that in the view of real automotive start-ups capacitive effects could not be considered as minor and a quasi-steady state description is not sufficient (Fig. SI-2). Relevantly, the oxygen reduction reaction at the cathode subsists in the first half of the MEA only, contributing in a significant way just in case of the very first segment. Cathodic ORR is not the limiting faradaic current during start-up, therefore not the keyelement to work on in order to reduce the degradation, as better illustrated in the next sections. This interpretation is supported by experimentally observing that the start-up profile is not altered either if air is constantly provided or if air flow is stopped, but with an airfilled cathode (Fig. SI-3).

Figures $5 \mathrm{a}$ and $5 \mathrm{~b}$ show also how the potential evolves at the anode side (dashed lines), while Figs. 6b and 6d separate the anodic current and charge terms respectively. The anodic local potential evolves through $(i)$ a first step of decrease, related to the doublelayer current peak, (ii) a second plateau-step, that subsists as long as ORR is occurring in that region of the anode catalyst layer and (iii) a third step of potential decrease, due to the hydrogen presence and its oxidation reaction, partially compensated by the complete reduction of the anodic catalyst surface and by the double-layer. Note also that, when the HOR starts in Fig. 6b, the anodic ORR shows a slight 

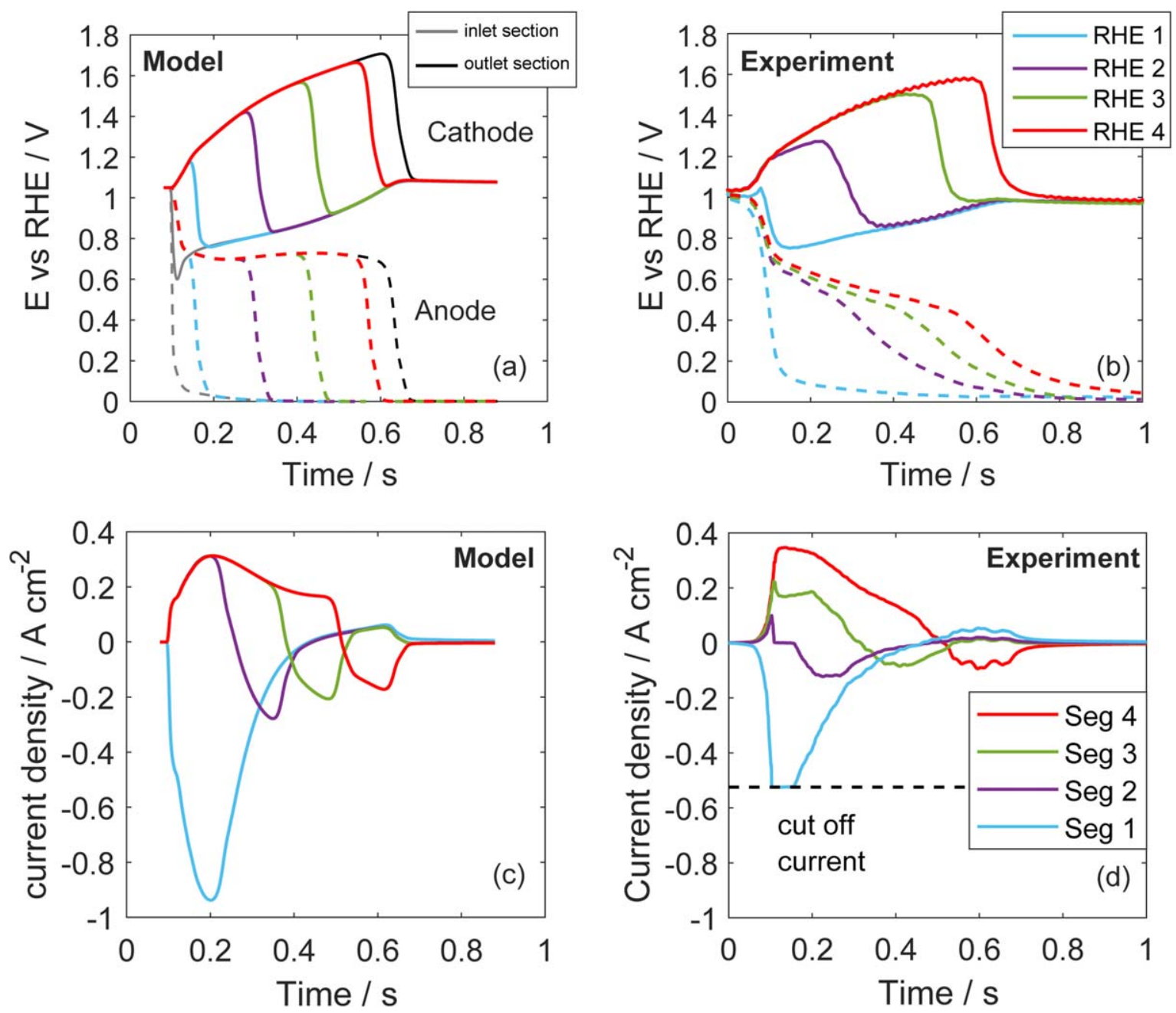

Figure 5. Reference start-up: model (left side) vs experiment (right side). $\mathrm{T}=30{ }^{\circ} \mathrm{C}$, $\mathrm{RH}=100 \% / 100 \%$ and anode dry flow equal to $175 \mathrm{nccm}$ (res. time of $0.5 \mathrm{~s}$ ). (a) and (b): local cathode (solid line) electrode potentials and local anode (dashed lines) electrode potentials for each RHE position during start-up transient. (c) and (d): total currents drawn by each segment during the transient.

increase in its absolute current value because of the direct reaction between hydrogen and oxygen catalyzed by platinum.

The less homogenous and less regular experimental trend of the internal currents compared to the simulation is the probable consequence of the flowfield geometry, i.e. a triple serpentine, characterized by different fluid dynamics with respect to the straight channels of the model. In particular, land/channels cause heterogeneities, as proved by some authors ${ }^{5,6,18}$; however, gas diffusion from the channel to the rib could not be described without a 3D model. This discrepancy between model and experiments regards, most of all, segment 2 and 3, for which the maximum current peak is however not clearly detected, since limited by the instrument current range according to the specifications provided in the experimental section. However, the focus is on segment 4 , well reproduced by the model: the clue point is simulating and understanding what happens at the outlet section, as the one that suffers most of carbon corrosion. In addition, the experimental process appears longer. The deviation is attributed to the relaxation mechanism associated to platinum oxides. Since the major differences in potential profiles, as visible in Fig. 5, are attributed to anode, a modelling limit could consists in the calibration of the anodic catalyst oxides reactions: their dynamic behaviour weights a lot in the light of the vary fast process under study. A dedicated calibration could improve the results, as explained later in the results section. On the other hand, discrepancies are again minor for the purpose of determining the amount of carbon corroded: the transient duration is indeed longer in a potential region where COR is not promoted.

The model succeeds in describing the most relevant physical processes and the stressors effects, as introduced in the following, with clear and coherent trends with respect to realistic experiments.

Analysis of stressors.-In literature, start-up duration is commonly described through the residence time. According to a plugflow model, a complete gas replacement is assumed at the anode side: the residence time corresponds to the time necessary to the inflow to completely fill the available volume. In this work, it is computed as in Eq. 20:

$$
t_{r e s}=\frac{V_{C}+V_{G D L}}{\dot{V}_{w e t(R H, T, P)}}=\frac{V_{C}+V_{G D L}}{\dot{V}_{0, d r y} \cdot \frac{T}{T_{0}} \cdot \frac{p}{p-p_{w}}}
$$

$\mathrm{V}_{\mathrm{C}}$ stands for the channels volume of the above-described triple serpentine flowfield, while $\mathrm{V}_{\mathrm{GDL}}$ is the available volume of the compressed GDL. Their values are $1.46 \mathrm{ml}$ and $2.07 \cdot 10^{-1} \mathrm{ml}$ respectively. Reference temperature $\mathrm{T}_{0}$ is $273.15 \mathrm{~K}$ and the reference pressure coincides to the ambient value $(101.325 \mathrm{kPa})$, that is the pressure condition assumed for all the transients. For the reference start-up case, the residence time results equal to $0.5 \mathrm{~s}$, which corresponds to a flow velocity of $1.25 \mathrm{~m} \mathrm{~s}^{-1}$. Actual process duration was estimated instead from the experimental data: from the local voltages, when all the RHE's reach a homogenous air 

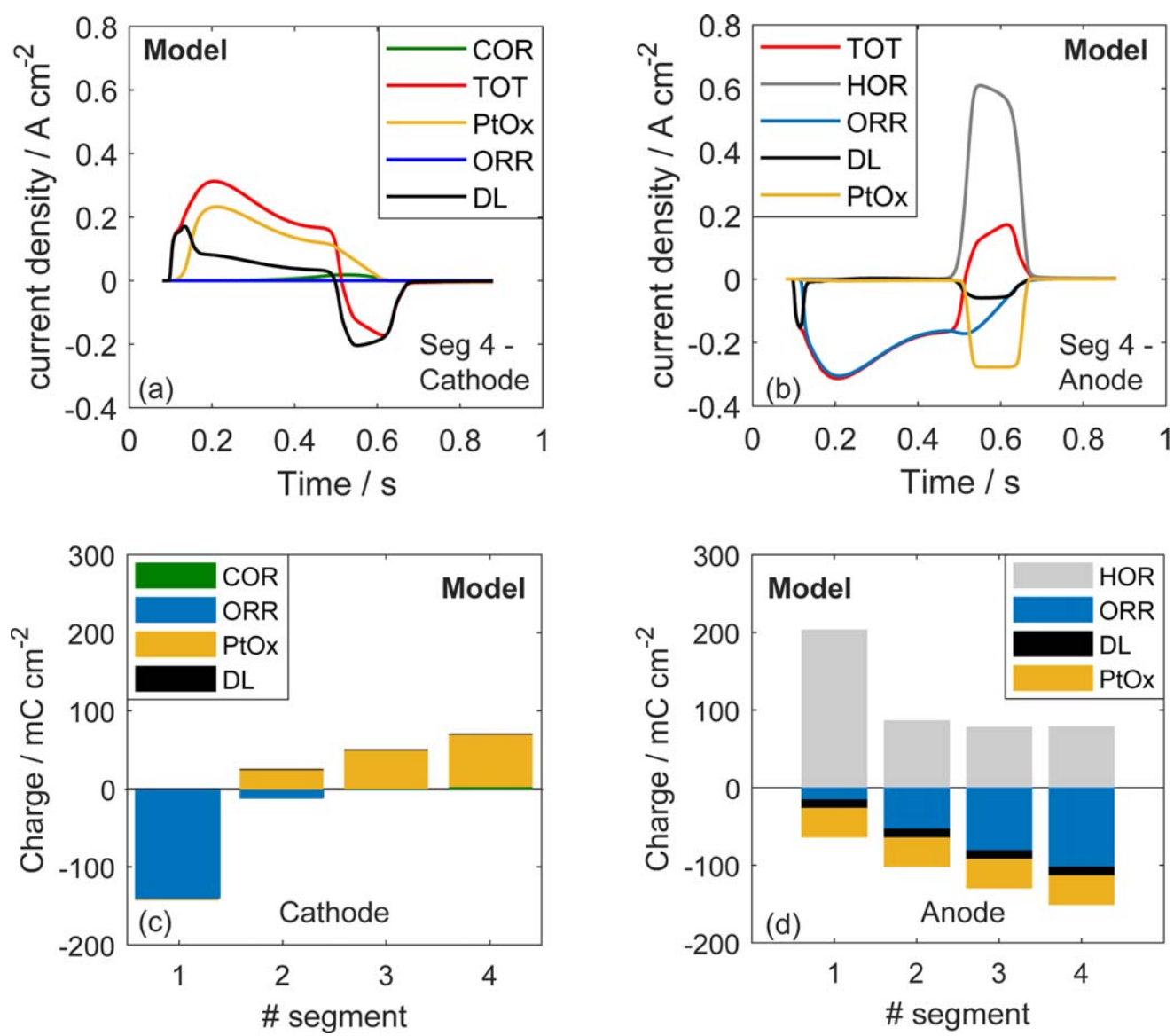

Figure 6. Reference start-up simulation. (a) Simulation results of current contributions at the cathode electrode and (b) at the anode electrode for the $4^{\text {th }}$ segment $\left(\mathrm{H}_{2}\right.$ outlet position). Positive values are due to oxidation reactions. (c) Reaction-specific charges computed for the whole electrode and a complete simulated start-up at the cathode. (d) Reaction-specific charges computed for the whole electrode and a complete simulated start-up at the anode.

potential, and from the in-plane currents, as all the segments show simultaneously a null value. The experimental profiles of the local potentials and of the internal currents highlight a reference process duration of about $0.67 \mathrm{~s}(\approx 35 \%$ longer than theoretical $)$ and this discrepancy is captured by the model (Fig. 5). Other authors ${ }^{26,53}$ proved that the theoretical residence time differs from the actual duration found in the experiment. In this work, we observed that the plug-flow assumption underestimates the transient duration. The discrepancy is probably caused by $(i)$ the consumption of hydrogen, that makes the fuel front to progress slower, (ii) the amount of oxygen that initially fills the anode, which must be consumed or discharged (as found later in case of diluted start-ups) and by (iii) rebalancing effects due to pseudo-capacitive contributions, that require a relaxation time: the lasting of the start-up is reduced by approximately $10 \%$ in case simulation is run without $\mathrm{PtOx}$ reactions (dashed line in Fig. SI-2). In this last case, since the response of the double-layer is faster rather than if Pt oxides are present, the local cathodic potential increases more rapidly. On the other hand, doublelayer contribution vanishes as soon as the voltage profile becomes flatter. As a consequence, the total charge involved in the process is lower compared to the simulation that implements PtOx contributions, as evident from the reduced in-plane currents, which clearly lack of a relevant input in the middle of the transient time (Fig. SI-2). The result is that less balancing charges are involved in the redistribution mechanism along the two electrodes, before reaching the final hydrogen/air condition.

Different dry flows have been tested while keeping constant the relative humidity and the temperature, as depicted in Fig. 7. At $30^{\circ} \mathrm{C}$ and $100 \% \mathrm{RH}$, the dry anode flows imposed are: $87.5 \mathrm{ml} \mathrm{min}^{-1}$, $175 \mathrm{ml} \mathrm{min}^{-1}, 350 \mathrm{ml} \mathrm{min}^{-1}$. They correspond respectively to a residence time of: $1 \mathrm{~s}, 0.5 \mathrm{~s}$ and $0.25 \mathrm{~s}$. The increase of the flow rate and, hence, the reduction of the residence time, impacts on the potential profile: not only the lasting of the phenomenon (and so of the high voltages) is reduced, but also a lower maximum potential is reached (e.g. $1.5 \mathrm{~V}$ for $350 \mathrm{ml} \mathrm{min}^{-1}$ ). This result is coherent with the experimental observations of Brightman and Hinds. ${ }^{40}$ On the other hand, larger internal currents are measured: the capacitive contributions increase as a consequence of a more rapid variation of the voltage profile. If the residence time is halved, from the $87.5 \mathrm{ml} \mathrm{min}^{-1}$ case (res. time $=1 \mathrm{~s}$ ) to the $175 \mathrm{ml} \mathrm{min}^{-1}$ case (res. time $=0.5 \mathrm{~s}$ ), the cathodic PtOx charge increases up to the $168 \%$. This is the result of the larger current peaks, even if the lasting of the transient is reduced, as visible comparing the full lines and the dashed lines in Figs. 7c and 7d.

Data were also obtained in case of several oxygen concentrations present in the anode channel, GDL and catalyst layer before the start-up, and related simulations carried out. Results are collected in Fig. 8. Oxygen concentration is a parameter of interest since air leakages that occur during the long stop time could result in different gas compositions. A lower oxygen concentration influences the polarization behaviour of the negative electrode, since it has a great impact on ORR: the anodic plateau-region in the air/air section of the MEA shifts towards a lower equilibrium potential, as represented in Figs. $8 \mathrm{a}$ and $8 \mathrm{~b}$. The voltage reduction at the anode helps in reducing the driving force for the reverse-current mechanism and the cathodic potential of the "passive" region drops down too; a minimum of $1.25 \mathrm{~V}$ is found for the nitrogen case (dotted line). As the oxygen concentration is decreased, also the internal currents are visibly mitigated, as collected by the experiments of Fig. 8d and reproduced by the model in Fig. 8c. Furthermore, the results obtained at very low oxygen concentrations, and most of all in the nitrogen case, revealed the impact of capacitive phenomena. Non- 

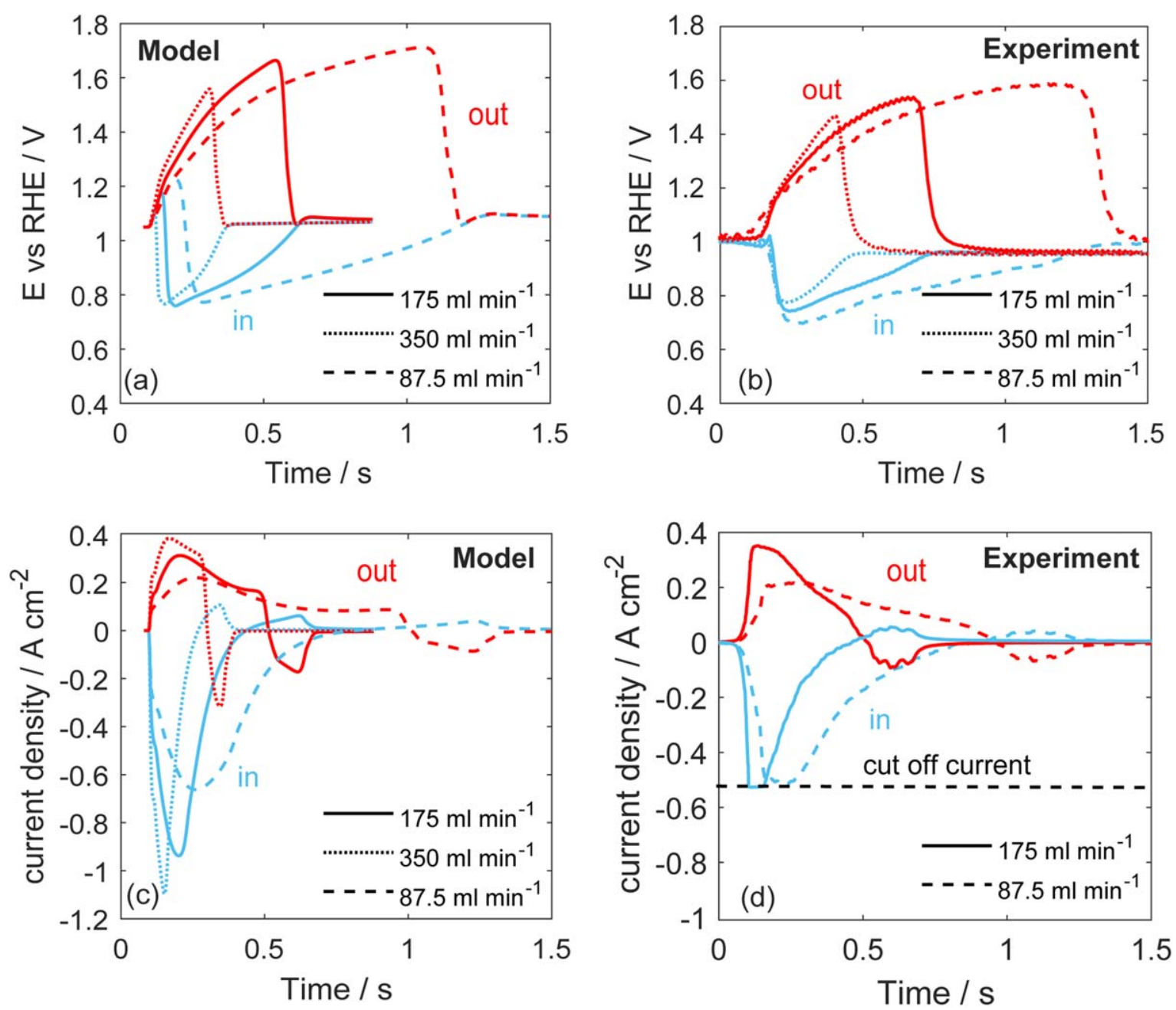

Figure 7. Effect of the $\mathrm{H}_{2}$ flow rate during the start-up. Comparison of the model results (left side) and the experimental results (right side) in case of: 87.5 , 175 and $350 \mathrm{ml} \mathrm{min}{ }^{-1}$. (a) and (b): impact of the flow rate on the local cathodic potentials. In red, RHE4 (out). In blue, RHE1 (in). (c) and (d): impact of the flow rate on the in-plane currents. In red, segment 4 (out). In blue, segment 1 (in).

negligible currents are measured: when the anodic ORR in the passive zone is switched off, the reverse-current is fed by the anodic double-layer and by the PtOx reactions. Indeed, even in presence of an inert atmosphere, the anode electrode starts from a potential close to the air equilibrium value because of the oxygen crossover, that makes the anodic Pt surface oxidized. At low oxygen partial pressures, the model seems less accurate in reproducing local measurements. Since the increased relevance of Pt oxides, this result should be caused by not-a-fully adequate description of the anodic pseudo-capacitive contributions. Indeed, all the kinetics have been scaled from cathode to anode through the roughness factor, thus it is speculated that a dedicated anodic calibration could improve the simulation results. All the collected profiles show also an increase of the duration of the start-up with the oxygen concentration, a trend that is matched by simulations. At low oxygen partial pressures, there is less amount of oxidant to remove. The process results to be faster since, even if the replacement is markedly plug-flow controlled, also the oxygen consumption plays a role, thanks to ORR and the direct reaction with the fuel. In addition, the rebalancing phenomena and the consequent relaxation time weight more when the potential peaks are greater at high oxygen percentages. Experimental time differences are slightly larger than modelled; probably this effect is enhanced by the oxygen trapped under the lands in the $3 \mathrm{D}$ geometry. ${ }^{6}$

The $30{ }^{\circ} \mathrm{C}$ case was chosen as reference until now, but higher temperature values $\left(40{ }^{\circ} \mathrm{C}, 60^{\circ} \mathrm{C}, 80^{\circ} \mathrm{C}\right)$ were tested and simulated as a comparison, to evidence the mitigating impact of the ambient temperature operation. From an experimental point of view, the controlled cell temperature was changed, while the relative humidity was held constant and equivalent to $100 \%$ for both anode and cathode. Since the variation of temperature at fully humidified conditions causes an increase of the partial pressure of water $\left(p_{w}\right)$, the dry flow rate was reduced to keep fixed the wet flow rate, to ensure the same residence time. This parameter was held constant since, as explained before, a change of the duration of the transient has a high impact on the permanence at high potentials and on capacitive/pseudo-capacitive effects. Four different temperatures, and so four different dry anode flows, were compared: $30{ }^{\circ} \mathrm{C}$ $\left(175 \mathrm{ml} \mathrm{min}^{-1}\right), 40{ }^{\circ} \mathrm{C}\left(164 \mathrm{ml} \mathrm{min}^{-1}\right), 60^{\circ} \mathrm{C}\left(133 \mathrm{ml} \mathrm{min}^{-1}\right), 80{ }^{\circ} \mathrm{C}$ $\left(83 \mathrm{ml} \mathrm{min}^{-1}\right)$ (Fig. SI-4). Exploiting the model, the $30{ }^{\circ} \mathrm{C}$ (full line) and the $80{ }^{\circ} \mathrm{C}$ (dashed line) cases were simulated and the results compared to experiments in Fig. 9. The stressor effect is reproduced in simulations, even though some differences subsist in the initial part of the transient, with a perceptible variance in terms of currents. First, both tests and simulations evidence higher cathode potential peaks and higher in-plane currents at ambient temperature. In particular, the maximum voltage decreases to $1.45 / 1.5 \mathrm{~V}$ at $80{ }^{\circ} \mathrm{C}$. These results are consequence of the complex dynamics of the process, as described below. Secondly, the transient at high temperature lasts more than at low temperature: this should be caused by the lower partial pressure of hydrogen, since the higher partial pressure of water, that slows down the progress of the front 

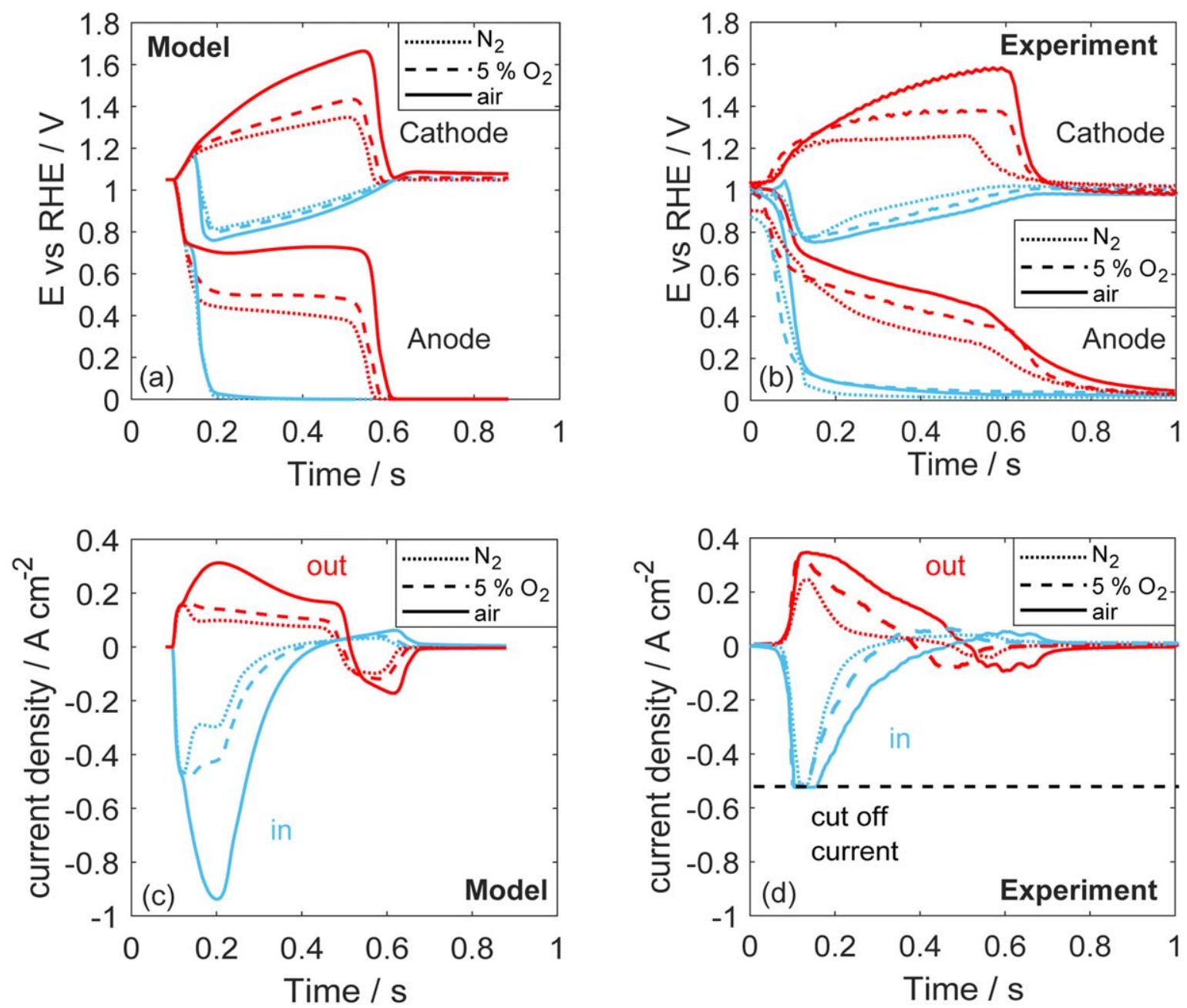

Figure 8. Effect of the oxygen dilution at the anode compartment during start-up. Comparison of the model results (left side) and the experimental results (right side) in case of: $\mathrm{N}_{2}, 5 \% \mathrm{O}_{2}$ and air. (a) and (b): impact of the oxygen dilution on both the cathodic and anodic potentials. In red, RHE4 (out). In blue, RHE1 (in). (c) and (d): impact of oxygen dilution on the in-plane currents. In red, segment 4 (out). In blue, segment 1 (in).

because of gas diffusion and consumption. Such deviation in the actual residence time between the two cases is reproduced by the model, even if underestimated. RHE1 gives a good indication for the active region of the cell: the minimum potential reached by the cathode is lower at high temperature. In other words, the overpotential for ORR is increased and the simulation estimates a $31 \%$ rise of its charge contribution over the entire start-up. Similarly, the others faradaic currents like ORR and HOR in anode are boosted, with a resulting charge increment of $43 \%$ and $8 \%$ respectively (charge values are averaged among segments) compared to the $30^{\circ} \mathrm{C}$ case. On the other hand, platinum oxidation reactions are affected by temperature too. The slower rate of change of the potentials in the longer high temperature process makes the pseudo-capacitive currents less relevant. Actually, their input at cathode is estimated to be reduced by the $29 \%$ and hence the initial passive current peak is lower at $80{ }^{\circ} \mathrm{C}\left(0.25 \mathrm{~A} \mathrm{~cm}^{-2}\right)$ rather than at $30{ }^{\circ} \mathrm{C}\left(0.35 \mathrm{~A} \mathrm{~cm}^{-2}\right)$. In order to understand if the difference in the current profile is due to either the cell temperature or the hydrogen partial pressure, relative humidity was studied as a stressor from an experimental point of view. In this case, the local electrode potential probes are not reported because the ionic path in the GDL is realized by means of a Nafion dispersion, which conductivity was affected by low RH values, making the measurement unreliable. Since the model did not include the water transport across the membrane it was also decided not to use it to interpret the experimental in-plane currents, here only briefly discussed. The shape of the current profile is unvaried for the two relative humidity values at $60{ }^{\circ} \mathrm{C}$ in Fig. SI-5, while it is different from the $30{ }^{\circ} \mathrm{C}$ process of Fig. $5 \mathrm{~d}$, resulting to be cell temperature-dependent. However, the current values are notably reduced in case of dry operation (dashed lines in Fig. SI-5). The effect could be ascribed to the ionic conductivity of the membrane and of the catalyst layer. The lower current peaks suggest a lower maximum potential during the transient since the reduced region related to catalyst oxides. The transient lasts less even if the wet flow rate was held constant. Probably, the higher partial pressure of hydrogen makes the real front to move faster. Moreover, the rebalancing effects are expected to impact less if the overall surface state of oxidation is lowered.

Amount of corroded carbon simulated by the model.-In case of start-up at reference conditions, the amount of corroded carbon predicted by the model is equivalent to $0.0326 \mu \mathrm{g}_{\mathrm{C}} \mathrm{cm}^{-2}$. Figure 10 summarizes the analysis of the stressors in terms of mass of carbon lost, considering the most relevant operating parameters. Stressor analysis revealed the key role of the residence time, that is the mainly impacting factor. Figure 10a shows an approximately exponential trend: as larger flow rates are introduced, the mitigation is ensured by both the reduction of the transient time and the reduction of the maximum potential peak. This first stressor proves that the experimental measurement of the in-plane currents is not enough for understanding the impact of start-ups in terms of support corrosion; as seen before indeed, current values increase by reducing the residence time. The COR contribution should be so separated, revealing in this case a larger carbon lost when the overall measured 

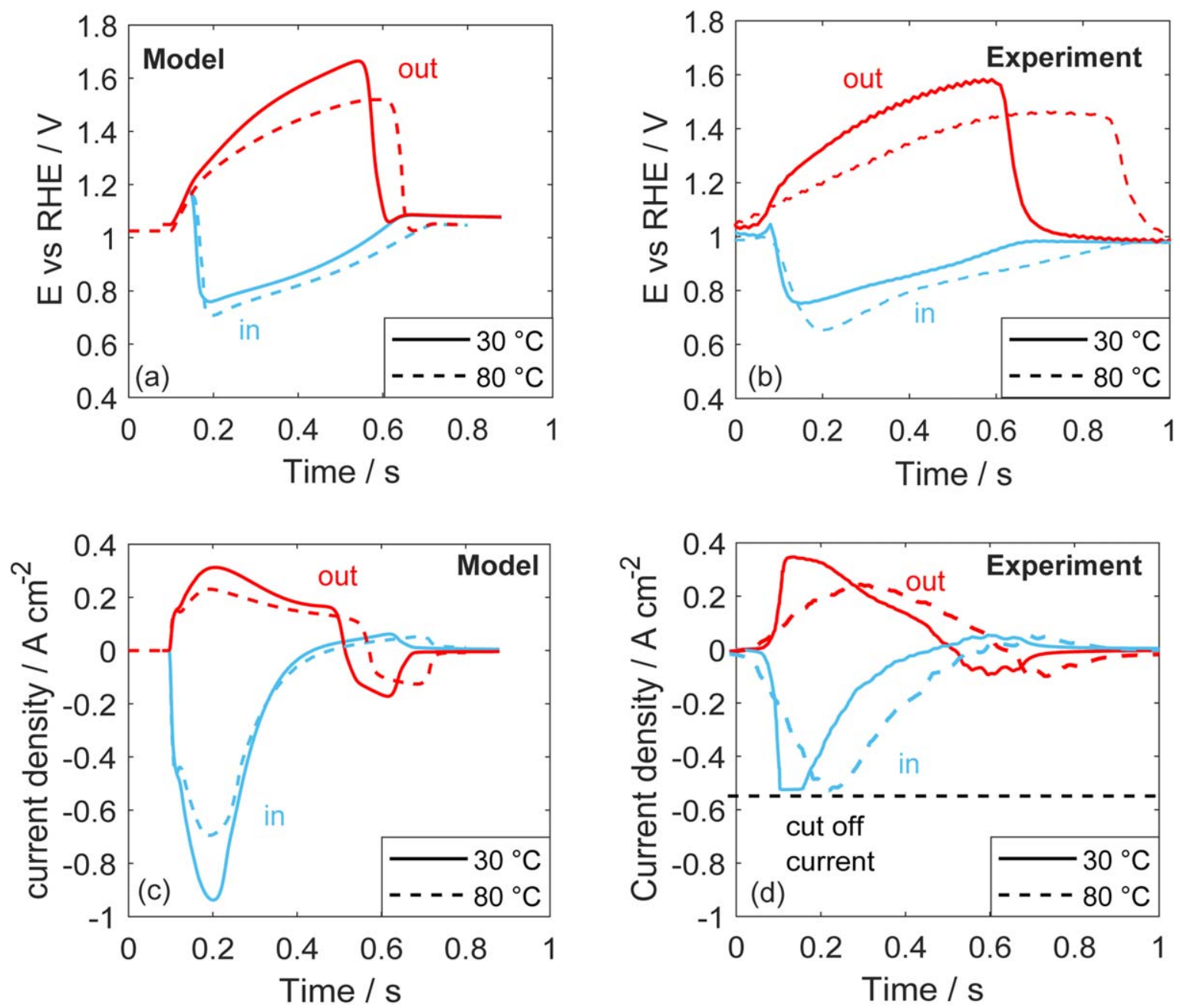

Figure 9. Effect of the cell operating temperature during the start-up. Comparison of the model results (left side) and the experimental results (right side). (a) and (b): impact of the temperature on the local cathodic potentials. In red, RHE4 (out). In blue, RHE1 (in). (c) and (d): impact of temperature on the in-plane currents drawn by each segment. In red, segment 4 (out). In blue, segment 1 (in).

currents are smaller. The trend obtained as an output of the modelling activity is consistent with $\mathrm{CO}_{2}$ measurements found in some literature works. ${ }^{16,29}$ Other authors ${ }^{36}$ evidenced a linear correlation of the degradation rate with the residence time; this is however a good estimation just in case the start-up maximum potential is not anymore flow rate-dependent, i.e. for sufficiently high residence times $(>1 \mathrm{~s}$, values out of application for automotive conditions), when the capacitive contributions weight less. Locally, an almost two regions degradation mechanism is evidenced, as visible in Fig. 10c: the first two segments are affected by a negligible amount of corroded carbon, as opposed to the half of the MEA closer to the anode outlet (segments 3 and 4 have a relative contribution of corroded carbon $>93 \%$, in all the cases). Even though the corrosion is reduced increasing the flow velocity, the degradation becomes more heterogeneous, shifting the impact towards the $4^{\text {th }}$ segment.

As described in the introduction, mitigation strategies that limit air starts are able to confine unavoidable hydrogen/air fronts at the ambient temperature, long time after system shut-down. According to the Arrhenius description of the temperature dependency of COR kinetics, the temperature decrease should reduce exponentially the impact of carbon corrosion. Coherently with patent literature and other studies, ${ }^{36,73}$ that identify the reduction of temperature as an effective strategy to reduce degradation, the amount of carbon oxidized is, as expected, lower in the start-up simulation at $30{ }^{\circ} \mathrm{C}$ rather than at $80{ }^{\circ} \mathrm{C}$. However, as widely described in the previous section, the mitigation effect of temperature is partially hindered by the increase of the potential peak at $30{ }^{\circ} \mathrm{C}$ compared to $80{ }^{\circ} \mathrm{C}$, at a fixed residence time. At the reference residence time of $0.5 \mathrm{~s}, \mathrm{a} \approx 2.5$ ratio in the carbon lost is found between the two cases. The effect of temperature is not constant as a function of residence time, as clearly visible in Fig. 10a. The difference between high and low temperature in terms of carbon lost is boosted as the residence time increases; since the capacitive contributions relatively weight less, the kinetics of COR becomes more crucial for longer processes.

Exploiting the model, the oxygen dilution at the anode has been compared to a possible oxygen cathodic dilution and to a combined dilution for both the sides, which results are reported in Fig. 10b. Among the tested dilutions, limiting the oxygen concentration in the anode side is the most effective strategy; the cathode voltage drop caused by the lowered oxygen partial pressure in anode ensures a steep reduction of the oxidized carbon. For example, a halved oxygen content at the anode decreases the amount of carbon corroded of the $79 \%$ respect to the air case. Also the cathodic dilution shows a beneficial effect on carbon lost because it hinders the fuel cell performance of the active cell region. Anyway, the reduction is less pronounced: a halved oxygen content at cathode reduces just of the $20 \%$ the corrosion charge respect to the reference case. Even when no oxygen is present either at the anode or at the cathode, completely inhibiting ORR, the oxygen crossover determines both the electrodes oxidation and the presence of capacitive/ pseudo-capacitive phenomena makes the potential $>1 \mathrm{~V}$ once the fuel is supplied, such that COR could not be completely avoided. 

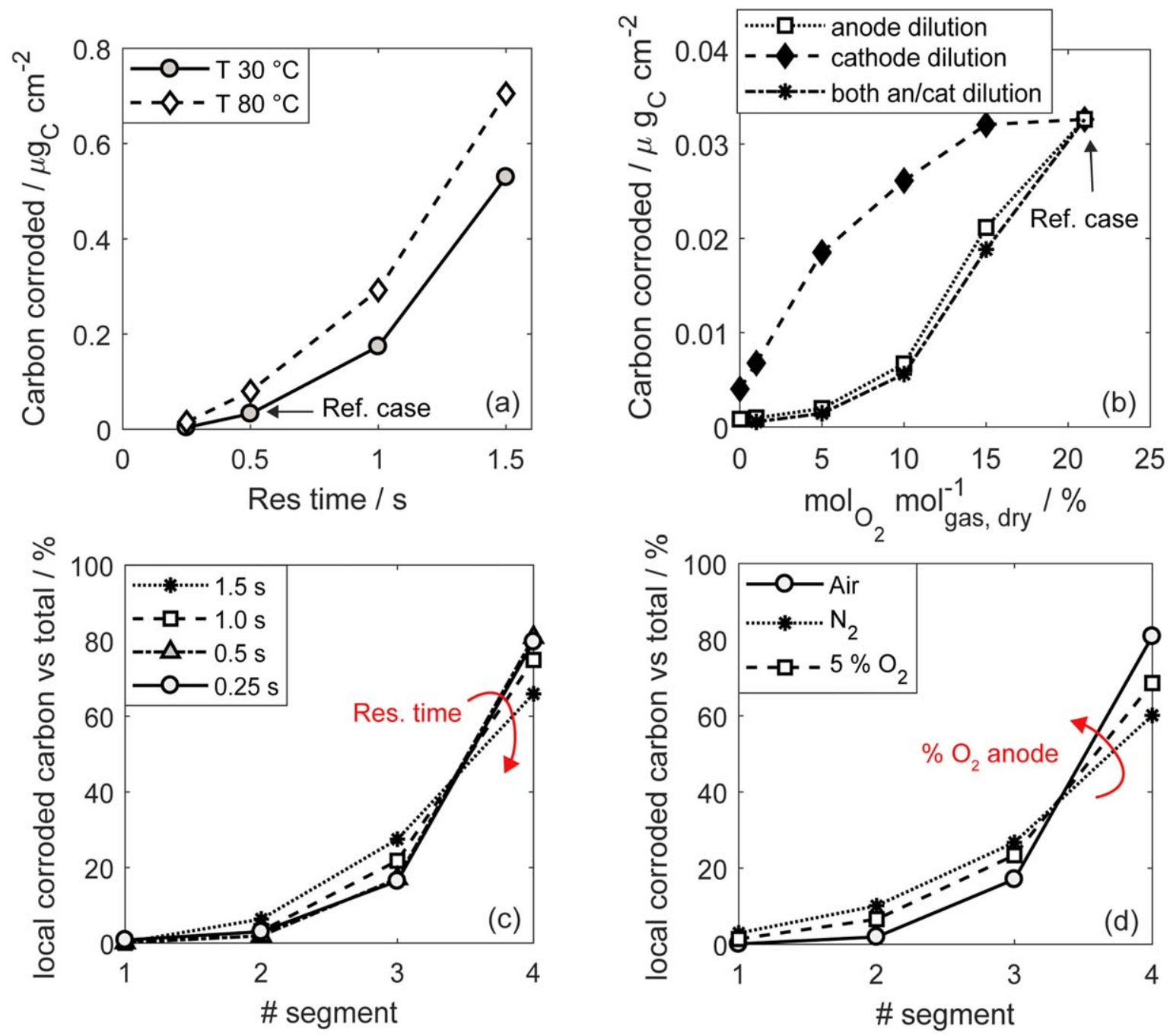

Figure 10. Amounts of corroded carbon simulated by the model during a start-up. (a) amount of carbon corroded as function of residence time and temperature (b) amount of carbon corroded as function of oxygen percentage: anode dilutions, cathode dilutions and combined dilutions are compared (c) single segment contribution to the whole amount of carbon corroded expressed as a percentage: different residence times are compared (d) single segment contribution to the whole amount of carbon corroded expressed as a percentage: different oxygen concentration at anode are compared.

The controlling role of the anode is evidenced when the dilution is combined at both the electrodes: the resulting trend of the corroded carbon is equivalent to the only-anode study. As a conclusion, the best practise to follow is to limit the air leakages and the oxygen crossover into the anode compartment; in addition, the local corrosion profile in Fig. 10d is smoothened, redistributing the impact over the catalyst layer surface.

Shut-down in the reference operative conditions. - In addition to start-up simulations and experiments, also shut-down in reference operative conditions was reproduced. The aim is to extend the validity of the conclusions also to this case, even though it is not of practical interest in the application. Parameters were kept equivalent to the start-up in order to ensure a direct comparison. At the temperature of $30{ }^{\circ} \mathrm{C}$ and fully humidified conditions, an air flow of $175 \mathrm{ml} \mathrm{min}^{-1}$ was introduced into the anode compartment, filled by pure hydrogen. The shut-down voltages and current profiles are depicted in Fig. 11. Once again, the model is able to mimic the main dynamic features of the transient, with a good agreement with the experimental results. This proves that the model covers transversally a large set of operations, and it is a useful tool to study the dynamics even in case of systems that do not implement comprehensive shutdown mitigations, or to verify the effectiveness of the applied stop strategies. Moreover, to the author's best knowledge, this is the first time that the physics of the shut-down process is simulated to reproduce in details potential profiles and internal currents, of which reaction-specific contributions are separated (Fig. SI-6). Literature review revealed not a unique conclusion about the impact of shutdown compared to start-up in terms of carbon corrosion: the majority of the works indicate shut-down as less serious, ${ }^{14,26}$ but others disclosed an higher damage.

In this work, an equivalent flow rate to start-up, and therefore an equivalent residence time, makes the shut-down to last more than $1 \mathrm{~s}$, so more than the start process. This should be caused, in part, by the lower diffusion of oxygen compared to hydrogen. Furthermore, it is observed a very long relaxation time in the transient end, when the homogenization of the $\mathrm{Pt}$ surface state is proceeding through the inversion of the internal current flow. The portion of the cathode electrode that faced potentials higher than air equilibrium needs to be reduced by providing some protons. Since in shut-down, at the process end, the anode is completely air filled, the proton providers are OER and, most of all, the oxidation reactions of platinum; catalyst oxidation occurs both in the cathode region that previously operated as active during the transient and in the anode. These reactions are much slower than HOR, that boosts the re-equilibration in the start case thanks to its fast kinetics. For our fast transient and corrosion resistant materials, the model predicts a carbon corroded 

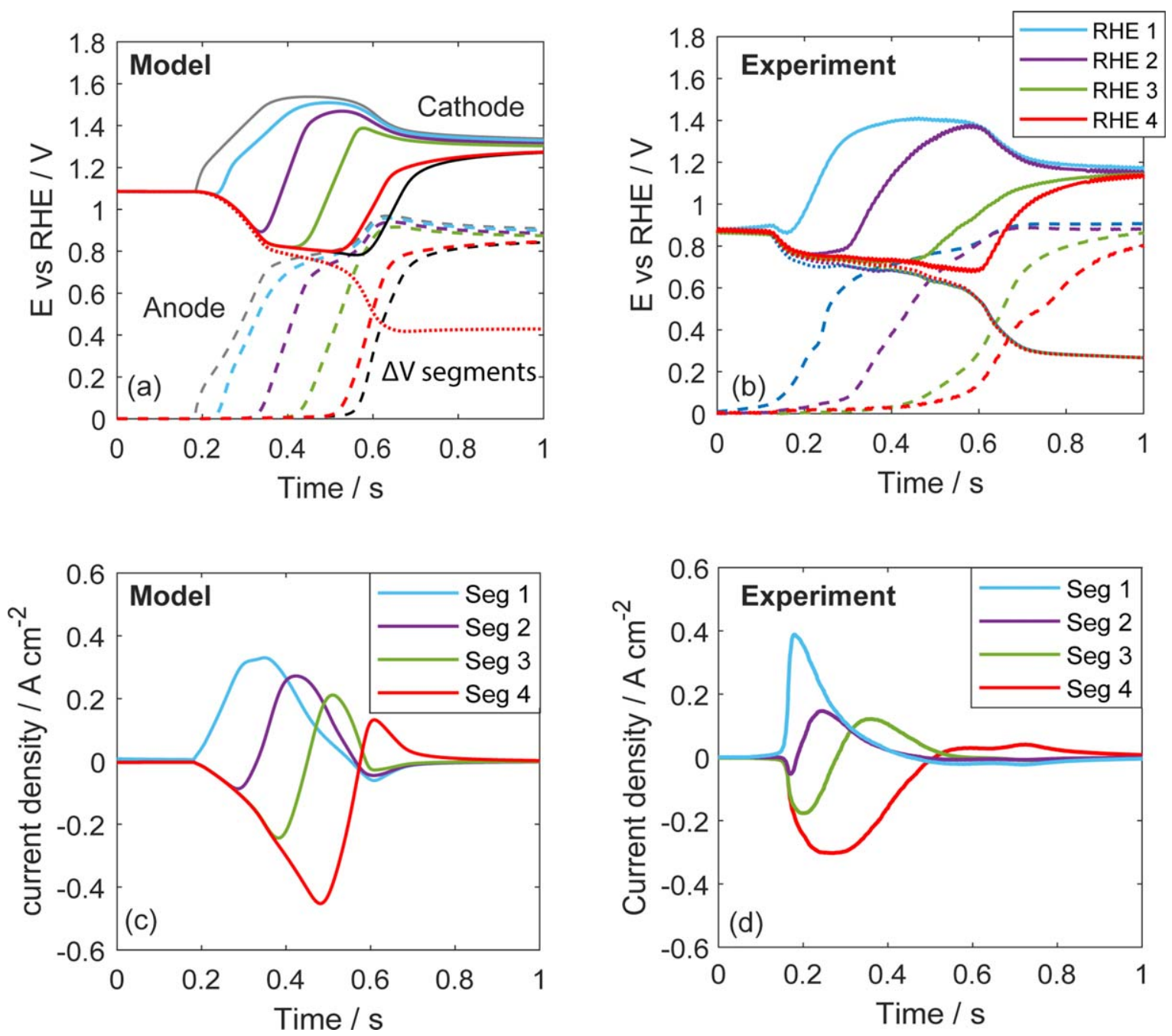

Figure 11. Reference shut-down: model (left side) vs experiment (right side). $\mathrm{T}=30{ }^{\circ} \mathrm{C}, \mathrm{RH}=100 \% / 100 \%$ and air anode dry flow equal to $175 \mathrm{nccm}$ (res. time of $0.5 \mathrm{~s}$ ). (a) and (b): local cathode (solid line) electrode potentials and local anode (dashed lines) electrode potentials for each RHE position during shut-down transient. Potential difference between the two electrodes is represented by dotted lines. (c) and (d): total currents drawn by each segment during the transient.

during shut-down that is much lower than start-up: just the $34 \%$ (simulation result: $0.0112 \mu \mathrm{g}_{\mathrm{C}} \mathrm{cm}^{-2}$ ).

\section{Conclusions}

A physical transient 2D model of PEMFC was developed to reproduce the dynamics of both start-up and shut-down. The model features a comprehensive description of both anode and cathode channels, as well as GDL's and CL's. Mass transport and kinetic sub-models were solved through the layers, by adopting adequate numerical schemes for the solution of the highly stiff problem. An adequate process of calibration of the model parameters was performed on polarization curves, limiting current measurements and voltammetry. Experimentally, an advanced setup is presented for combining local potentials and internal currents measurements, in order to guarantee a detailed description of the start/stop evolution even for the very fast transients that match the automotive specifications. Local potentials were captured by an array of through-plate Reference Hydrogen Electrodes applied on a macrosegmented hardware: state-of-the-art air automotive starts (i.e. at low temperature and low residence time) increase the cathode potential to values as high as $1.6 \mathrm{~V}$. Cathodic potential peak is mainly controlled by the anode oxygen concentration and it should be reduced to a value of $1.25 \mathrm{~V}$ in case of nitrogen. The currents exchanged in-plane among the segments were measured in an innovative way by three high-precision source-measure modules: they evidenced the generated/consumed charges even for very fast fronts, with the high time resolution of ms. Internal currents are as high as $0.35 \mathrm{~A} \mathrm{~cm}^{-2}$ in the passive region and estimated to reach around $0.9 / 1 \mathrm{~A} \mathrm{~cm}^{-2}$ in the active region. The combined information of voltage and current makes evident when a MEA portion shifts from passive to active, as well as when the re-balancing effect is dominant.

Detailed insights of kinetic, transport and pseudo-capacitive processes were obtained through the modelling activity. To the best of our knowledge, what presented in this work is one of the most complete start-up/shut-down models validated on operando voltage and current measurements over a wide range of operating conditions. The model captures the process heterogeneity: only the $4^{\text {th }}$ segment is significantly impacted by carbon corrosion, while only in the $1^{\text {st }}$ ORR evolves at the cathode side. Catalyst oxides, in particular at cathode, raised as crucial: neglecting pseudo-capacitive contributions does not offer an accurate description of the process in the light of the fast transients analyzed in this work. Indeed, pseudocapacitive inputs contribute most to the positive currents measured for the cathode catalyst layer. COR starts to be relevant only close to the maximum voltage and when the potential declines from the peak because of the combined driving force of $(i)$ high voltage values and (ii) extra amounts of protons required by double-layer and Pt oxides at cathode. 
The final objective was the evaluation of mitigation strategies in order to help optimizing start-up protocols through adequate operating conditions. A high flow rate reduces both the transient duration and the maximum voltage peak, having a doubled positive impact: the rate of the fuel introduction during an air start is crucial for attenuating the carbon support degradation. In addition, the oxygen concentration analysis exhibited the key role played by the anode side. Reducing oxygen concentration at anode is more convenient than at cathode: air leakages into the anode compartment should be avoided, as well as oxygen crossover. Low temperatures, close to ambient value, reduce the amount of carbon corroded because of the hindered COR kinetic, but the beneficial outcome is partially lost since higher voltages are reached during the start-up, for a given residence time.

Finally, the consistency between simulated and experimented results highlighted the general validity of the model, that could be exploited for the analysis of stop strategies too.

A still open question lies in the impact of the catalyst oxidation state on the dissolution of platinum during repeated start-ups. Even if dissolution currents per cycle are low, the present work highlighted the fundamental role played by platinum oxides, in a potential region that is dominated by the place exchange mechanisms. ${ }^{66,74}$ The realistic and very fast air starts under study could make the effect of platinum depletion and/or agglomeration relevant for ageing. About this topic, the reader should refer to other works. ${ }^{58}$ Therefore, a further model development consists in describing how the processes observed during start-up evolve during degradation and in coupling the support corrosion model with platinum dissolution to assess the relative impact of the two ageing mechanisms.

\section{Acknowledgments}

This work has been developed in the framework of the European ID-FAST project, which has received funding from the Fuel Cells and Hydrogen 2 Joint Undertaking under the European Union's Horizon 2020 research and innovation program (grant agreement No. 779565).

\section{ORCID}

Elena Colombo (iD https://orcid.org/0000-0002-2288-8704 Andrea Bisello (iD https://orcid.org/0000-0002-1313-3078 Andrea Casalegno (iD https://orcid.org/0000-0002-3396-4979 Andrea Baricci (D) https://orcid.org/0000-0003-2331-7222

\section{References}

1. F. A. De Bruijn, V. A. T. Dam, and G. J. M. Janssen, Fuel Cells, 8, 3 (2008).

2. R. Borup et al., Chem. Rev., 107, 3904 (2007).

3. C. A. Reiser, L. Bregoli, T. W. Patterson, J. S. Yi, J. D. Yang, M. L. Perry, and T. D. Jarvi, Electrochem. Solid-State Lett., 8, A273 (2005).

4. S. Maass, F. Finsterwalder, G. Frank, R. Hartmann, and C. Merten, J. Power Sources, , 176, 444 (2008)

5. J. Durst, A. Lamibrac, F. Charlot, J. Dillet, L. F. Castanheira, G. Maranzana, L. Dubau, F. Maillard, M. Chatenet, and O. Lottin, Appl. Catal. B Environ., 138-139, 416 (2013).

6. I. A. Schneider and S. von Dahlen, Electrochem. Solid-State Lett., 14, B30 (2011).

7. Y. Ishigami, K. Takada, H. Yano, J. Inukai, M. Uchida, Y. Nagumo, T. Hyakutake, H. Nishide, and M. Watanabe, J. Power Sources, 196, 3003 (2011).

8. S. Kreitmeier, A. Wokaun, and F. N. Büchi, J. Electrochem. Soc., 159, F787 (2012)

9. A. M. Chaparro, P. Ferreira-Aparicio, M. A. Folgado, E. Brightman, and G. Hinds, J. Power Sources, 325, 609 (2016).

10. H. Schulenburg, B. Schwanitz, N. Linse, G. G. Scherer, A. Wokaun, J. Krbanjevic, R. Grothausmann, and I. Manke, J. Phys. Chem. C, 115, 14236 (2011).

11. L. Castanheira, W. O. Silva, F. H. B. Lima, A. Crisci, L. Dubau, and F. Maillard, ACS Catal., 5, 2184 (2015).

12. F. Ettingshausen, J. Kleemann, A. Marcu, G. Toth, H. Fuess, and C. Roth, Fuel Cells, 11, 238 (2011)

13. J. P. Meyers and R. M. Darling, J. Electrochem. Soc., 153, A1432 (2006)

14. W. Gu, R. N. Carter, P. T. Yu, and H. A. Gasteiger, ECS Trans., 11, 963 (2007).

15. W. Gu, P. T. Yu, R. N. Carter, R. Makharia, and H. A. Gasteiger, Modeling and Diagnostics of Polymer Electrolyte Fuel Cells, ed. C.-Y. Wang and U. Pasaogullari (Springer New York, New York, NY) p. 45 (2010).

16. G. Maranzana, A. Lamibrac, J. Dillet, S. Abbou, S. Didierjean, and O. Lottin, J. Electrochem. Soc., 162, F694 (2015).

17. J. Chen, J. Hu, and J. R. Waldecker, J. Electrochem. Soc., 162, F878 (2015).
18. B. Randrianarizafy, P. Schott, M. Gerard, and Y. Bultel, Energies, 13, 10 (2020)

19. T. Zhang, P. Wang, H. Chen, and P. Pei, Appl. Energy, 223, 249 (2018).

20. Y. Yu, H. Li, H. Wang, X. Z. Yuan, G. Wang, and M. Pan, J. Power Sources, 205 10 (2012).

21. P. Ren, P. Pei, Y. Li, Z. Wu, D. Chen, and S. Huang, Prog. Energy Combust. Sci., 80, 100859 (2020).

22. B. Wickman, H. Grönbeck, P. Hanarp, and B. Kasemo, J. Electrochem. Soc., 157, B592 (2010)

23. K. H. Lim, H. S. Oh, S. E. Jang, Y. J. Ko, H. J. Kim, and H. Kim, J. Power Sources, 193, 575 (2009).

24. A. Ofstad, J. Davey, S. Sunde, and R. L. Borup, ECS Trans., 16, 1301 (2019).

25. A. P. Young, V. Colbow, D. Harvey, E. Rogers, and S. Wessel, J. Electrochem. Soc., 160, F381 (2013).

26. J. Dillet, D. Spernjak, A. Lamibrac, G. Maranzana, R. Mukundan, J. Fairweather, S. Didierjean, R. L. Borup, and O. Lottin, J. Power Sources, 250, 68 (2014).

27. Y. Y. Jo, E. Cho, J. H. Kim, T. H. Lim, I. H. Oh, S. K. Kim, H. J. Kim, and J. H. Jang, J. Power Sources, 196, 9906 (2011).

28. J. H. Kim, E. A. Cho, J. H. Jang, H. J. Kim, T. H. Lim, I. H. Oh, J. J. Ko, and S. C. Oh, J. Electrochem. Soc., 157, B104 (2010).

29. N. Linse, G. G. Scherer, A. Wokaun, and L. Gubler, J. Power Sources, 219, 240 (2012).

30. B. Wang et al., J. Hydrogen Energy, 44, 13737 (2019).

31. N. Macauley, D. D. Papadias, J. Fairweather, D. Spernjak, D. Langlois, R. Ahluwalia, K. L. More, R. Mukundan, and R. L. Borup, J. Electrochem. Soc., 165, F3148 (2018).

32. R. J. Balliet and C. A. Reiser, United States Patent, US, 6835479 B2.

33. L. L. Van Dine, M. M. Steinbugler, C. A. Reiser, and G. W. Scheffler, United States Patent Application Publication, US, 2002/0098393 A1.

34. P. T. Yu, F. T. Wagner, G. W. Skala, B. Lakshmanan, and J. P. Salvador, United States Patent, US, 8492046 B2.

35. Y. Takagi and Y. Takakuwa, ECS Trans., 3, 855 (2019)

36. T. Mittermeier, A. Weiß, F. Hasché, G. Hübner, and H. A. Gasteiger, J. Electrochem. Soc., 164, F127 (2017).

37. T. Mittermeier, A. Weiß, F. Hasché, and H. A. Gasteiger, J. Electrochem. Soc., 165 F1349 (2018).

38. P. Ferreira-Aparicio, A. M. Chaparro, M. A. Folgado, J. J. Conde, E. Brightman, and G. Hinds, ACS Appl. Mater. Interfaces, 9, 10626 (2017).

39. Y. Qiu, H. Zhong, M. Wang, and H. Zhang, J. Power Sources, , 283, 171 (2015).

40. E. Brightman and G. Hinds, J. Power Sources, , 267, 160 (2014).

41. Z. Siroma, N. Fujiwara, T. Ioroi, S. Ichi Yamazaki, H. Senoh, K. Yasuda, and K. Tanimoto, J. Power Sources, 172, 155 (2007)

42. R. Lin et al., J. Hydrogen Energy, 45, 1030 (2020)

43. Y. Yang, W. Li, R. Lin, S. Xia, and Z. Jiang, J. Power Sources, , 404, 126 (2018).

44. Q. Zhang, R. Lin, X. Cui, S. X. Xia, Z. Yang, and Y. T. Chang, J. Power Sources, 341, 230 (2017).

45. F. Jia, L. Guo, and H. Liu, Int. J. Energy Res., 43, 3768 (2019)

46. A. Lamibrac, G. Maranzana, O. Lottin, J. Dillet, J. Mainka, S. Didierjean, A. Thomas, and C. Moyne, J. Power Sources, 196, 9451 (2011).

47. A. Lamibrac, G. Maranzana, J. Dillet, O. Lottin, S. Didierjean, J. Durst, L. Dubau, F. Maillard, and M. Chatenet, Energy Procedia, 29, 318 (2012).

48. C. Rabissi, P. Gazdzicki, L. Guétaz, S. Escribano, L. Grahl-Madsen, A. Baricci, and A. Casalegno, J. Power Sources, , 397, 361 (2018).

49. C. Rabissi, M. Zago, P. Gazdzicki, L. Guétaz, S. Escribano, L. Grahl-Madsen, and A. Casalegno, J. Power Sources, , 404, 135 (2018).

50. P. Piela, T. E. Springer, J. Davey, and P. Zelenay, J. Phys. Chem. C, 111, 6512 (2007).

51. C. Rabissi, E. Brightman, G. Hinds, and A. Casalegno, Int. J. Hydrogen Energy, 41, 18221 (2016)

52. C. Rabissi, E. Brightman, G. Hinds, and A. Casalegno, Int. J. Hydrogen Energy, $\mathbf{4 3}$ 9797 (2018).

53. G. Hinds and E. Brightman, Electrochem. Commun., 17, 26 (2012).

54. T. A. Greszler, D. Caulk, and P. Sinha, J. Electrochem. Soc., 159, F831 (2012).

55. N. Nonoyama, S. Okazaki, A. Z. Weber, Y. Ikogi, and T. Yoshida, J. Electrochem. Soc., 158, B416 (2011).

56. P. P. Lopes, D. Tripkovic, P. F. B. D. Martins, D. Strmcnik, E. A. Ticianelli, V. R. Stamenkovic, and N. M. Markovic, J. Electroanal. Chem., 819, 123 (2018).

57. D. R. Baker, D. A. Caulk, K. C. Neyerlin, and M. W. Murphy, J. Electrochem. Soc., 156, B991 (2009).

58. A. Bisello, E. Colombo, A. Baricci, C. Rabissi, L. Guetaz, P. Gazdzicki, and A. Casalegno, J. Electrochem. Soc., 168, 054501 (2021).

59. T. Bednarek and G. Tsotridis, Data in Bief, 31105945 (2020).

60. T. Bednarek and G. Tsotridis, J. Power Source, 473, 228319 (2020).

61. K. C. Neyerlin, W. Gu, J. Jorne, and H. A. Gasteiger, J. Electrochem. Soc., 154, B631 (2007)

62. K. C. Neyerlin, W. Gu, J. Jorne, and H. A. Gasteiger, J. Electrochem. Soc., 153, A1955 (2006).

63. A. Pandy, Z. Yang, M. Gummalla, V. V. Atrazhev, N. Y. Kuzminyh, V. I. Sultanov, and S. Burlatsky, J. Electrochem. Soc., 160, F972 (2013).

64. K. G. Gallagher, D. T. Wong, and T. F. Fuller, J. Electrochem. Soc., 155, B488 (2008).

65. P. T. Y. M. F. Mathias et al., Interfaces, 14 (2005).

66. B. E. Conway, B. Barnett, H. Angerstein-Kozlowska, and B. V. Tilak, J. Chem Phys., 93, 8361 (1990).

67. R. M. Darling and J. P. Meyers, J. Electrochem. Soc., 150, A1523 (2003).

68. R. Vetter and J. O. Schumacher, J. Power Sources, 438 (2019). 
69. S. Litster, W. K. Epting, E. A. Wargo, S. R. Kalidindi, and E. C. Kumbur, Fuel Cells, 13, 935 (2013).

70. R. Vetter and J. O. Schumacher, Comput. Phys. Commun., 13, 935 (2019).

71. E. L. Redmond, B. P. Setzler, F. M. Alamgir, and T. F. Fuller, Phys. Chem. Chem. Phys., 16, 5301 (2014).
72. S. G. Rinaldo and M. Eikerling, J. Phys. Chem., 114, 5773 (2010).

73. A. Oyarce, E. Zakrisson, M. Ivity, C. Lagergren, A. B. Ofstad, A. Bodén, and G. Lindbergh, J. Power Sources, , 254, 232 (2014).

74. Barathram Jayasankar and Kunal Karan, Electrochimica Acta, 273, 367-78 (2018). 